\title{
Mapping the birch and grass pollen seasons in the UK using satellite sensor time-series
}

Nabaz R. Khwarahm*1,2, Jadunandan Dash ${ }^{2}$, C. A. Skjøth ${ }^{3}$, R. M.Newnham ${ }^{4}$, B. Adams-

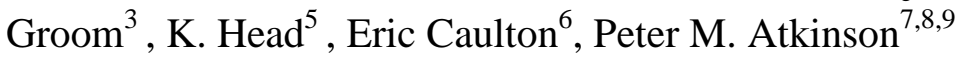

${ }^{1}$ University of Sulaimani, College of Science Education, Biology Department, Sulaimani, Kurdistan Regional Government (KRG)

${ }^{2}$ Global Environmental Change and Earth Observation Research Group, Geography and Environment, University of Southampton, Highfield, Southampton SO17 1BJ, UK

*nabaz.khwarahm@univsul.edu.iq; khwarahm21302@itc.nl

${ }^{3}$ National Pollen and Aerobiology Research Unit, University of Worcester, Henwick Grove, Worcester, WR2 6AJ, UK

${ }^{4}$ School of Geography, Environment \& Earth Sciences, Victoria University of Wellington, PO Box 600, Wellington, New Zealand

${ }^{5}$ School of Geography, Earth \& Environmental Sciences, University of Plymouth, Plymouth, $U K$

${ }^{6}$ Centre Director \& Hon. University Research Fellow, Scottish Centre for Pollen Studies, Edinburgh Napier University, School of Life Science, Edinburgh, UK

${ }^{7}$ Faculty of Science and Technology, Engineering Building, Lancaster University, Lancaster LAI 4YR, UK

${ }^{8}$ Faculty of Geosciences, University of Utrecht, Heidelberglaan 2, 3584 CS Utrecht, The Netherlands

${ }^{9}$ School of Geography, Archaeology and Palaeoecology, Queen's University Belfast, BT7 INN, Northern Ireland, UK 


\section{Abstract}

Grass and birch pollen are two major causes of seasonal allergic rhinitis (hay fever) in the UK and parts of Europe affecting around $15-20 \%$ of the population. Current prediction of these allergens in the UK is based on (i) measurements of pollen concentrations at a limited number of monitoring stations across the country and (ii) general information about the phenological status of the vegetation. Thus, the current prediction methodology provides information at a coarse spatial resolution only. Most station-based approaches take into account only local observations of flowering, while only a small number of approaches take into account remote observations of land surface phenology. The systematic gathering of detailed information about vegetation status nationwide would therefore be of great potential utility. In particular, there exists an opportunity to use remote sensing to estimate phenological variables that are related to the flowering phenophase and, thus, pollen release. In turn, these estimates can be used to predict pollen release at a fine spatial resolution. In this study, time-series of MERIS Terrestrial Chlorophyll Index (MTCI) data were used to predict two key phenological variables: the start of season and peak of season. A technique was then developed to estimate the flowering phenophase of birch and grass from the MTCI time-series. For birch, the timing of flowering was defined as the time after the start of the growing season when the MTCI value reached $25 \%$ of the maximum. Similarly, for grass this was defined as the time when the MTCI value reached $75 \%$ of the maximum. The predicted pollen release dates were validated with data from nine pollen monitoring stations in the UK. For both birch and grass, we obtained large positive correlations between the MTCI-derived start of pollen season and the start of the pollen season defined using station data, with a slightly larger correlation observed for birch than for grass. The technique was applied to produce detailed maps for the flowering of birch and grass across the UK for each of the years from 2003 to 2010. The results demonstrate that the remote sensing-based maps of onset flowering of birch and grass for the UK together with the pollen forecast from the Meteorology Office and National Pollen and Aerobiology Research Unit (NPARU) can potentially provide more accurate information to pollen allergy sufferers in the UK.

Keywords: Aerobiology, Phenology, Grass pollen, Birch pollen, Hay fever, Predicting model, MERIS MTCI, Onset of Birch flowering, Onset of Grass flowering, Onset of greenness 


\section{Introduction}

Early prediction of allergenic pollen concentration in the air can be valuable for medical professionals, allergy sufferers and pharmaceutical companies. The increasing prevalence of allergenic diseases, mainly hay fever, triggered by aeroallergens affects hundreds of millions of people worldwide (Bousquet et al., 2008). In the United Kingdom, the most common types of allergenic pollen are birch and grass which, respectively, affect approximately $25 \%$ and $95 \%$ of the population of hay fever sufferers (Emberlin et al., 1999). The most common species of birch in the UK are Downy birch (Betula pubescens) and Silver birch (Betula pendula). The former is the most abundant birch in Scotland and North West England. In contrast, Silver birch is most common species in the South and South East England. In the UK, there are about 150 species of grass of which around 12 species contribute significant amounts of pollen to the atmosphere. This high number of species makes prediction of grass pollen difficult (Emberlin, 2009). In the UK and parts of Europe the overall prevalence of hay fever is approximately 15-20\% (Emberlin et al., 1997; Aas et al., 1997; Varney et al., 1991). The highest prevalence occurs in late adolescence/early adulthood, with between 8 and 35\% of young adults in the European Union having IgE (Immunoglobulin E) serum antibodies to grass pollen (Burr, 1999; D'Amato, 2000). High prevalence rates were recorded for many parts of the world, both for grass and birch pollen (Bousquet et al., 2007). The prevalence of sensitivity to grass and birch allergens varies geographically depending on the source abundance and the amount of allergen extract on the pollen (Buters et al., 2012). The length of the grass and birch pollen seasons also varies both spatially and temporally. This is due to variation in the factors that influence the abundance and dispersal of pollen such as local vegetation type, altitude, land use and climate ( Galán et al., 1995; Emberlin et al., 1997; Emberlin et al., 1999; Emberlin et al., 2000). Europewide, grass pollen is the most widely spread aeroallergen with the highest concentrations in the Western Iberian Peninsula, central Europe and the UK (Skjøth et al., 2013a).

Birch and grass aeroallergen concentrations in the UK are usually predicted based on current and past meteorological data together with pollen concentration data collected at a specific pollen station, landuse, topography, local phenological observations and empirical research (Adams-Groom et al., 2002; Emberlin et al., 2007; Skjoth et al,. 2015a; Skjoth et al., 2015b). The predictions in some parts of Europe are also partially established using empirical models (Laaidi, 2001; Chuine and Belmonte, 2004; García-Mozo et al., 2009; Smith et al., 2009), sometimes in conjunction with pollen dispersion simulation models such as COSMO-Art, for example, which is currently used in Switzerland (Zink et al., 2012, 2016). Empirical models are well-known 
for their limitations as they are specific to the area where they are produced (Stach et al., 2008), such as large urban areas like London (Smith and Emberlin, 2005a) and Copenhagen (Skjøth et al., 2008a), that are known to have a warmer climate compared to their surroundings. Moreover, the spatial representation of these prediction models is low as pollen grains are generally collected from a limited number of pollen monitoring sites . Within the urban environment, gardens and small woodlands are considered to be an important source of birch pollen in the atmosphere of cities (Skjøth et al., 2008b) and urban environments often have advanced flowering during spring compared to the surrounding rural landscape due to the urban heat island effect (Estrella et al., 2006; Neil and $\mathrm{Wu}, 2006)$. Similarly, grass areas are commonly found in or near urban areas (Pauleit and Duhme, 2000) and it has been shown that these urban sources can cause considerable variation in the grass pollen load throughout the urban landscape (Skjøth et al., 2013b). Any characterisation of flowering and overall pollen concentration obtained using a fixed and small number of pollen sampling stations will therefore be limited. Additional information about grass phenology and in turn the timing of their pollen release at finer spatial resolution would therefore be highly useful. For the UK, this is particularly relevant due to its unique composition; a patchy landscape that includes some of the largest urban areas in Europe (Skjøth et al., 2013b). Over the last three decades development of new satellite sensors and availability of these data at a high temporal frequency provided the opportunity to estimate vegetation phenological variables at regional to global scale (Lloyd, 1990; Reed et al., 1994; Fisher and Mustard, 2007; Roerink et al., 2011; Jeganathan et al., 2014).

Phenological variables derived from temporal profiles of satellite-derived vegetation indices can be used to characterize the stages of vegetation development during the growing season (Olsson et al., 2005; Heumann et al., 2007; Seaquist et al., 2009; Reed et al., 2009; Beurs de and Henebry, 2010 ; Roerink et al., 2011). Thus, they can be related to biological definitions of plant phenology, for example, the flowering phenophase related to pollen release. Satellite sensor imagery has the advantage that it provides spatially complete coverage that can be used to interpolate traditional ground-based phenological observations. Linkosalo $(1999,2000)$ found in southern Finland that the difference in time from birch (Betula pendula) male flowering to the first date of budburst was only 1.1 days, with male flowering occurring first. Thus, the timings of male flowering and leaf budburst of birch are well correlated $(r=0.97)$. Moreover, the timing of male flowering, leaf budburst and pollen release appear to be quite closely synchronised (Newnham et al., 2013). This indicates that birch phenophases, observed as leaf budburst or, for example, greenness of birch trees, could be used to determine the timing of local birch pollen release. This suggests that measurements of the flowering phenophase of grass and birch from remote sensing could be used to map local pollen release nationwide (Karlsen et al., 2009). 
Satellite sensor images have been used widely to detect variables related to vegetation phenology, for example, the start of season and end of season (Lloyd, 1990; Reed et al., 1994; Fisher and Mustard, 2007; Dash et al., 2010; Roerink et al., 2011), but to a lesser extent for the flowering phenophases which for some species are during or before budburst (e.g. for birch) and for others are at a different growth stage (e.g. for grass). One reason may be related to the fact that phenological phases at the species level are most easily observed with remote sensing in areas where the observational target (e.g. birch) is the dominant species. This is the case for birch in Scandinavia (Skjøth et al., 2008b), while oak and beech outnumber birch in most other European countries including England (Skjøth et al., 2008b). Similar results have therefore not been produced in other European countries, although mapping of birch flowering could be very useful. It is therefore important to explore if flowering phenophases can be estimated indirectly with remote sensing. One approach could be to investigate if the overall increase in leaf area index and chlorophyll concentration in woodland areas with a mixed composition of trees correlates well with birch flowering during spring. A similar argument can be used for grass considering that foliage development for most grasses precedes flower blooming.

Several studies have used time-series satellite-driven vegetation indices to characterise important phenological variables related to pollen release. Hogda et al., (2002) used coarse spatial resolution satellite sensor data, specifically the Global Inventory Monitoring and Modeling System (GIMMS) Normalized Difference Vegetation Index (NDVI), to characterize the start of birch pollen season in Fennoscandia. They related the NDVI time-series with birch pollen concentration data from five stations, and reported significant positive correlation coefficients $(r)$ in the range 0.55 to 0.85 . They used maximum value GIMMS NDVI time-series data (i.e., $8 \mathrm{~km}$ spatial resolution and 15-day compositing period) to compute the mean NDVI value (NDVI >0) for each pixel of birch land cover. Then, the time when the NDVI value exceeds the mean threshold was used to determine the onset of the pollen season each year. The middle day of the last 15 day period before passing the threshold was used as the starting date of the pollen season. Similarly, Karlsen et al., (2009) used finer spatial resolution satellite sensor data, specifically MODIS (Moderate Resolution Imaging Spectroradiometer) NDVI with $250 \mathrm{~m}$ spatial resolution and 16-day compositing to determine the start of birch flowering in Norway. They reported large significant positive correlations in the range 0.78 to 0.92 between station pollen concentration data and the start of birch flowering. They determined the onset of the birch season from mean values of MODIS NDVI time-series, specifically when the NDVI value each year exceeded $0.85 \%$ of the July $12^{\text {th }}$ to August $28^{\text {th }}$ mean. Furthermore, Luvall et al. (2011) used the MODIS Enhanced Vegetation Index (EVI) to characterise the start of juniper species flowering in the Southern Rocky Mountains in the USA, a plant also 
categorized as an aeroallergen. They reported that EVI has the capability to detect inter-annual variation in the juniper pollen season and showed close agreement with ground-based pollen observations. The exact methodology of determining the start of juniper plant species flowering from the study of Luvall et al., (2011) is embargoed to be published online. Such studies are very limited, and further investigation of methods to generate links between flowering phenophase and pollen was necessary.

Boyd et al., (2011) tested various vegetation indices; MERIS global vegetation index (MGVI), MODIS NDVI and MODIS EVI and the Medium Resolution Imaging Spectrometer (MERIS) Terrestrial Chlorophyll Index (MTCI) (Dash and Curran, 2004; Dash et al., 2010) in studying vegetation phenology in the UK and recommended use of MTCI for phenological studies mainly due to its sensitivity to canopy chlorophyll content.. Thus, MTCI is related directly to canopy chlorophyll content, a function of chlorophyll concentration and leaf area index (LAI) and, therefore, is a useful proxy for the canopy physical and chemical alterations associated with phenological change (Dash et al., 2008).

The use of spectral reflectance bands in the red edge wavelengths and sensitivity to changes in chlorophyll content related to different phenological events make MTCI a useful product for monitoring overall greenness and phenological changes at regional to global scale (Dash and Curran, 2004). The MTCI is defined as the ratio of the difference in reflectance (R) between band 10 and band 9 and the difference in reflectance between band 9 and band 8 of the MERIS standard band setting.

$$
\mathrm{MTCI}=\mathrm{R}_{753.75}-\mathrm{R}_{708.75} / \mathrm{R}_{708.75}-\mathrm{R}_{681.25}
$$

Where, $\mathrm{R}_{753.75}, \mathrm{R}_{708.75}, \mathrm{R}_{681.25}$ are the reflectances in the centre wavelengths ( $\mathrm{nm}$ ) of the MERIS standard band setting in bands 10, 9 and 8. The MTCI is a standard L2 MERIS product and is produced from the L2 normalised surface reflectance in bands 8, 9, 10 of the MERIS sensor (Dash, 2010).

The main objective of this paper was to predict the onset of flowering phenophase related to the timing of pollen release for birch and grass for the whole UK from time-series MTCI data and investigate its relationship with pollen concentrations at nine pollen monitoring sites across the country. We suggest outputs from this research , 
used together with the pollen forecast from the UK Met Office, can provide useful and reliable information to pollen allergy sufferers in the UK.

\section{Materials and methods}

\subsection{Dataset and study area}

To address the objectives of this research three types of data were used. These are : (1) 8-year (2003-2010) historic pollen data (pollen $\mathrm{m}^{-3}$ ) for both grass and birch at nine stations across the UK (i.e. study area (Figure 1)) (2) 8-year (2003-2010) MTCI Level 3 product satellite sensor data and (3) CORINE land cover map as a reference for landcover information.

\subsubsection{Pollen concentration data}

Time-series for both grass and birch pollen concentration data (daily average pollen grains $\mathrm{m}^{-3}$ ) for the 20032010 period were taken from nine pollen monitoring sites in the UK (Figure 1). The data were provided by the National Pollen and Aerobiology Research Unit (NPARU) at the University of Worcester. These monitoring sites sample across much of the UK's regional diversity in climate, land cover and distance from the coast (Table 1). All pollen data were obtained using standardised methods (BAF 1995) involving Hirst design samplers (Hirst, 1952). Grass and birch pollen are readily distinguishable from one another. However, most grass pollen grains share the same general appearance, being spheroid and monoporate (pollen grains with a single pore on the surface), and are not routinely distinguished beyond family level. As a consequence, UK grass pollen grains are a composite total of $\sim 150$ species of grass, although only around 12 species significantly contribute pollen to the atmosphere (Emberlin et al., 1999). Similarly, birch pollen grains in the UK represent mostly the two common species, Downy birch (Betula pubescens) and Silver birch (Betula pendula), both of which produce triporate (three pores on the pollen surface) grains with a smooth to a slightly granular surface texture (Emberlin, 2009) that are not readily distinguished from one another.

The Hirst design pollen sampler has a built-in vacuum pump that sucks in pollen and other particles through an entrance orifice (i.e. active sampling). Behind the orifice there is a revolving drum covered with an adhesivecoated, transparent plastic tape. Particles in the air impact on the tape to produce a time-varying sample (Emberlin et al., 2000). After its removal from the trap, the tape is divided into segments corresponding to 24 hour periods. The segments are then examined under a light microscope and an identification and counting procedure is applied. In the UK, pollen grains are counted along twelve latitudinal transects (Smith et al., 2009). 
The samplers are usually placed on the roof of a tall building mostly $10 \mathrm{~m}$ above the ground, with no obstacles around the building. The pollen concentration data presented for each year were the daily average pollen concentration (pollen $\mathrm{m}^{-3}$ ) for each station with most of the data available during the pollen season. The remainder of the year had either no data or a very low pollen concentration; these data need to be excluded to avoid bias in the statistical analysis (Smith et al., 2009). Three techniques were applied to estimate the start and end dates of the pollen season after the data were smoothed (only for derivative method (DM)) using a seven day moving average. The cumulative sum technique of Driessen et al., (1990) was used to determine the start dates of the birch and grass pollen seasons. These are defined as the day when the cumulative daily average pollen concentration (grains $\mathrm{m}^{-3}$ ) reaches a threshold of 75 (for birch) and 125 (for grass) and are referred to as cumulative $\Sigma 75$ and cumulative $\Sigma 125$. This technique is useful in forecasting as it does not rely on retrospective data (i.e., does not depend on data from the previous year) compared to other methods such as the total annual catch threshold (e.g., of $1 \%, 2.5 \%$ and $5 \%$ ), which requires the total pollen catch of the previous season (Emberlin, 2009).

In addition, a derivative method (DM) (Khwarahm et al., 2014) was used to define the start and end of both the grass and birch seasons. The derivative method is based on the inflection point which is the point on a curve where the curvature changes sign from positive to negative or vice versa. Additionally, the peak days where the highest counts of pollen were recorded are also indicated. First, the pollen concentration datasets were smoothed using a seven-day moving average and then the first derivative was calculated. The start of the pollen season was defined as the date when the first derivative was greater than five and remained positive for five consecutive days. Similarly, the end of season was defined as the date when the first derivate was less than five and remained negative for five consecutive days after the peak date (day with largest count of pollen). The justification for a derivative threshold is based on the clinically significant amount of pollen that induces allergy: the definition used is that the six-day cumulative amount of pollen is at least 30 pollen $\mathrm{m}^{-3}$. This concentration of birch or grass pollen has been classified as moderate (25-50 pollen $\mathrm{m}^{-3}$ ) by NPARU (National Pollen and Aerobiology Research Unit) based at the University of Worcester in the UK. According to NPARU, most sufferers develop an allergic manifestation when birch or grass pollen reaches the moderate category (25-50 pollen $\mathrm{m}^{-3}$ in the air). A similar argument may be given for the end of the season except that in most cases the end of the pollen season is longer (longer tail), probably due to re-suspension of pollen or pollen re-flotation . Most importantly, this technique is not species-specific and also provides information on the end of the pollen season. 


\subsubsection{Landcover data}

The Corine Land Cover 2000 (CLC2000) 100 m, version 9/2007 in TIFF raster format (European Commission, 2005) was used as a reference for grass and birch source areas (European Environment Agency (EEA) (http://www.eea.europa.eu)). The product provides coverage for most of Western Europe with $100 \mathrm{~m}$ spatial resolution. The data were resampled to the MTCI pixel size (i.e. $0.0089^{\circ}(\sim 1 \mathrm{~km}$ by $\sim 1 \mathrm{~km})$ ) using a majority function and reclassified to five important classes which are seen as significant in their contribution to atmospheric pollen and can be considered as pollen sources for birch and grass. The classes were broadleaf forest, mixed forest and, green urban area for birch, and grassland and pasture for grass. After the data were processed it was decided to aggregate the grassland and pasture classes together as the main source of grass pollen. Despite the fact that the grassland and pasture classes have differences in structure and management approach, they have quite similar spectral signals. 


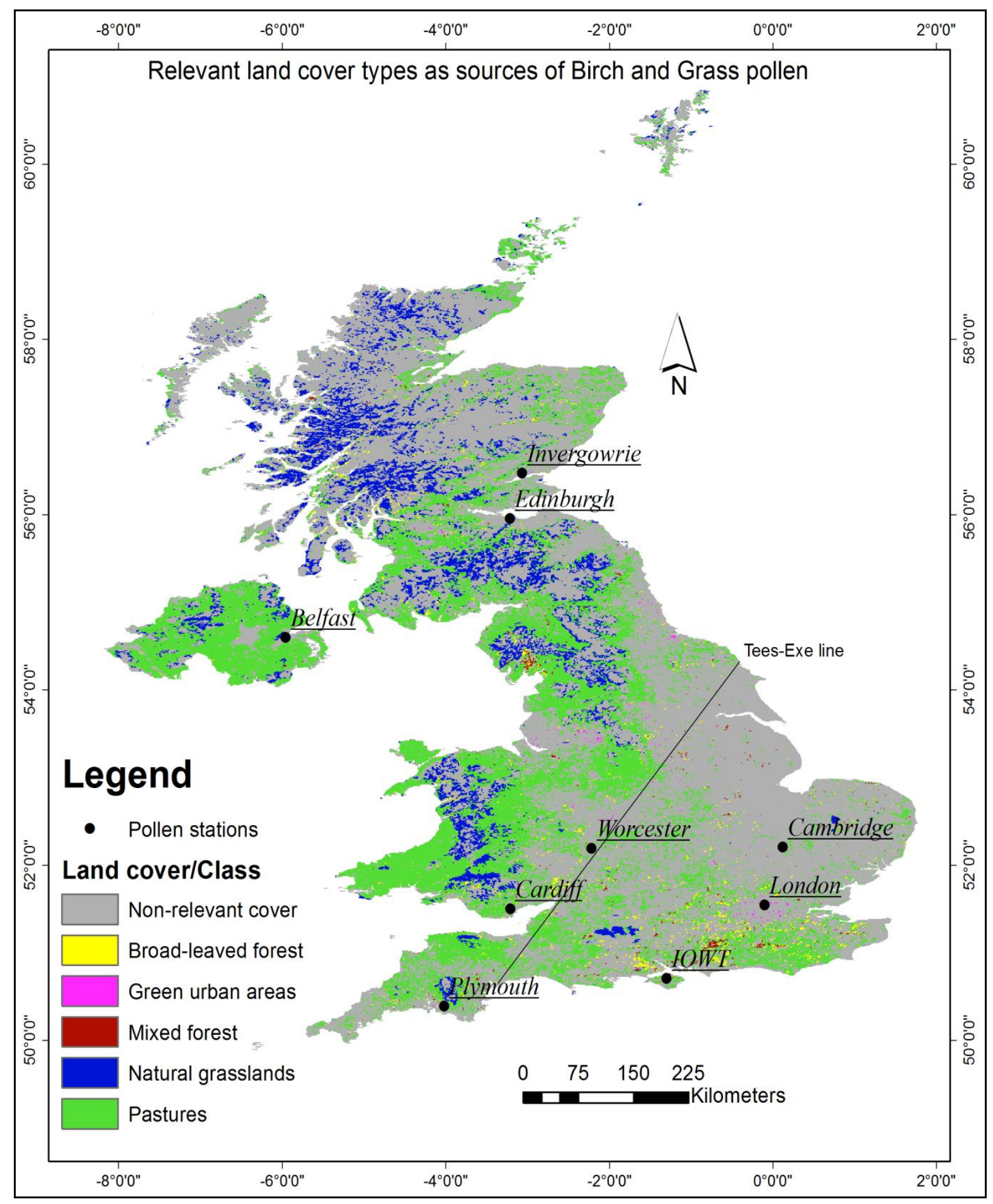

Figure 1. Source land cover types relevant to grass and birch and the location of the pollen monitoring stations. Source: (European Environment Agency (EEA) (http://www.eea.europa.eu))

\subsubsection{MTCI data}

A time-series of MTCI data (level 3 arithmetic mean composite) was obtained from the NERC Earth Observation Data Centre for the period 2003- 2010 (http://neodc.nerc.ac.uk). These data sets are supplied by the 
European Space Agency (ESA) and processed by the Geo-Intelligence division of Airbus Defence and Space. The composites were produced from standard MERIS L2 MTCI products using an arithmetic mean compositing and resampled into $0.0089^{\circ}(\sim 1 \mathrm{~km}$ by $\sim 1 \mathrm{~km})$ grid using a fast flux conversion algorithm. The algorithm uses the fast Sutherland-Hodgeman area clipping method to resample the orbital pixels into the desired grid (Sutherland and Hodgman, 1974).

The MTCI data were composed of two sets: the 2003- 2007 period was represented by an 8 days composite with 46 images and the 2008- 2010 period was represented by a decadal composite with 36 images for each year. The data were available in GEOTIFF format with latitude-longitude geocoded grids, accompanied by an XML metadata file and a JPEG browse image.

The MTCI time-series data were processed by applying techniques described and discussed by Dash et al. (2010). The methods are briefly: (i) identifying and removing low-quality pixels caused by noise, (ii) filling data gaps with linear interpolation, (iii) smoothing images with the discrete Fourier transform (DFT), and (iv) estimating the phenological parameters (see section 2.2.1).

Data smoothing was used to remove any residual cloud contamination and noise coming from the compositing and re-sampling procedures without compromising the phenological signal information in the time-series data. Careful consideration needs to be given to the choice of smoothing method (Boyd et al., 2011). There are several smoothing approaches for interpolation of removed erroneous or missing data in a time-series satellite product. An example is Gaussian model fitting in the Timesat software programme (Jönsson and Eklundh, 2004). This approach has been used to remove noise in the composite data whilst preserving phenological event information (Jönsson and Eklundh, 2002).

Hird and McDermid, (2009) compared various smoothing approaches statistically and reported that the double logistic and asymmetric Gaussian fitting methods performed comparatively more accurately. Some further approaches are: best index slope extraction (BISE) (Viovy et al., 1992), median filters (Vandijk et al., 1987), splines and weighted least-squares (White et al., 2005), discrete Fourier transformation (DFT) (Jakubauskas et al., 2001; Geerken et al., 2005), locally adjusted cubic-splines (Chen et al., 2006), and the double logistic function (Zhang et al., 2004). More recently, Roerink et al., (2011) used HANTS (Harmonic Analysis of NDVI Time Series) to process and analyse time-series satellite sensor data. The HANTS algorithm is based on the least-squares curve fitting of cosine-functions (Atkinson et al., 2012). 
Here, the MTCI stacks were smoothed using the DFT with four harmonics (Jakubauskas et al., 2001). According to this approach a complete reconstruction of the phenological signals from the Fourier transform needs to consider the appropriate number of harmonics needed to capture a naturally varying phenological cycle. This study focuses on determining the onset of greenness and the end of season and it has been demonstrated that the first four harmonics can adequately capture these variables for natural vegetation (Dash et al., 2010). The Fourier transform approach has the advantage of minimal user input (Dash et al., 2010) and has been applied to many regional-to-global AVHRR time-series datasets (e.g., the Fourier-adjusted, sensor and solar zenith angle corrected, interpolated, reconstructed (FASIR) dataset (Los et al., 2000), and the temporal Fourier analysis (TFA) dataset (Hay et al., 2006)).

\subsection{Method description}

First, we developed a technique to define the onset of flowering for both birch and grass using the MTCI data at a spatial resolution of $0.0089^{\circ}(\sim 1 \mathrm{~km}$ by $\sim 1 \mathrm{~km})$ from the MERIS sensor. Second, we employed three methods for defining the onset of the birch and grass pollen seasons from pollen count data for nine pollen sites distributed across the UK. Third, we explored the relationship between the onset of flowering and the onset of the grass and birch pollen seasons. Fourth, we generated two maps for the UK at $1 \mathrm{~km}$ spatial resolution, which show the spatial variability of the onset of flowering for birch and grass for the period 2003-2010. Finally, we validated these maps with ground pollen count data.

\subsubsection{Estimating phenological variables from MTCI data}

From the smoothed MTCI data stacks phenological parameters were estimated for the entire UK for each pixel across each of the eight years under investigation. The phenological parameters included onset of season (or onset of greenness), onset of flowering and peak of season for the most relevant land cover types (i.e. broadleaf forest, grassland). Broadleaf forest is regarded as a source of birch pollen and grassland as a source of grass pollen.

Several quantitative methods exist to extract variables related to vegetation phenology, for example: inflection point methods, trend derivative methods and threshold-based methods (Reed et al., 1994; Beurs de and Henebry, 2010). The inflection point phenology method is based on detecting points where maximum curvature occurs in a plotted time-series of vegetation indices, the trend or curve derivative phenology method attempts to identify points of departure between the original vegetation temporal signal and a derivative curve, and threshold-based 
methods use either a pre-defined or relative reference value to define phenology transition dates (Lloyd, 1990; Fisher and Mustard, 2007 ). In this study, the inflection point approach of Dash et al., (2010) was used to derive key phenological parameters for two reasons: (i) it has the advantage of being easy to implement and also permits discrimination of multiple growing seasons for land cover types with multiple growth seasons such as crops (Reed et al., 1994) and (ii) one of the methods of defining the start of pollen season from pollen concentrationdata was the derivative method (DM) (see pollen concentration data), which is also based on the inflection point method. As a single phenology cycle following a smooth sinusoidal pattern, onset of season was defined as a valley point at the beginning of the growing cycle, peak of a season was defined as the maximum value of MTCI, and end of senescence was defined as a valley point occurring at the decaying end of the phenology cycle (figure 2). The onset of flowering for birch was defined as the time after the onset of the growing season when the MTCI value reaches $25 \%$ of the maximum. Similarly for grass this was defined as the time when MTCI reached $75 \%$ of the maximum (section 2.2).

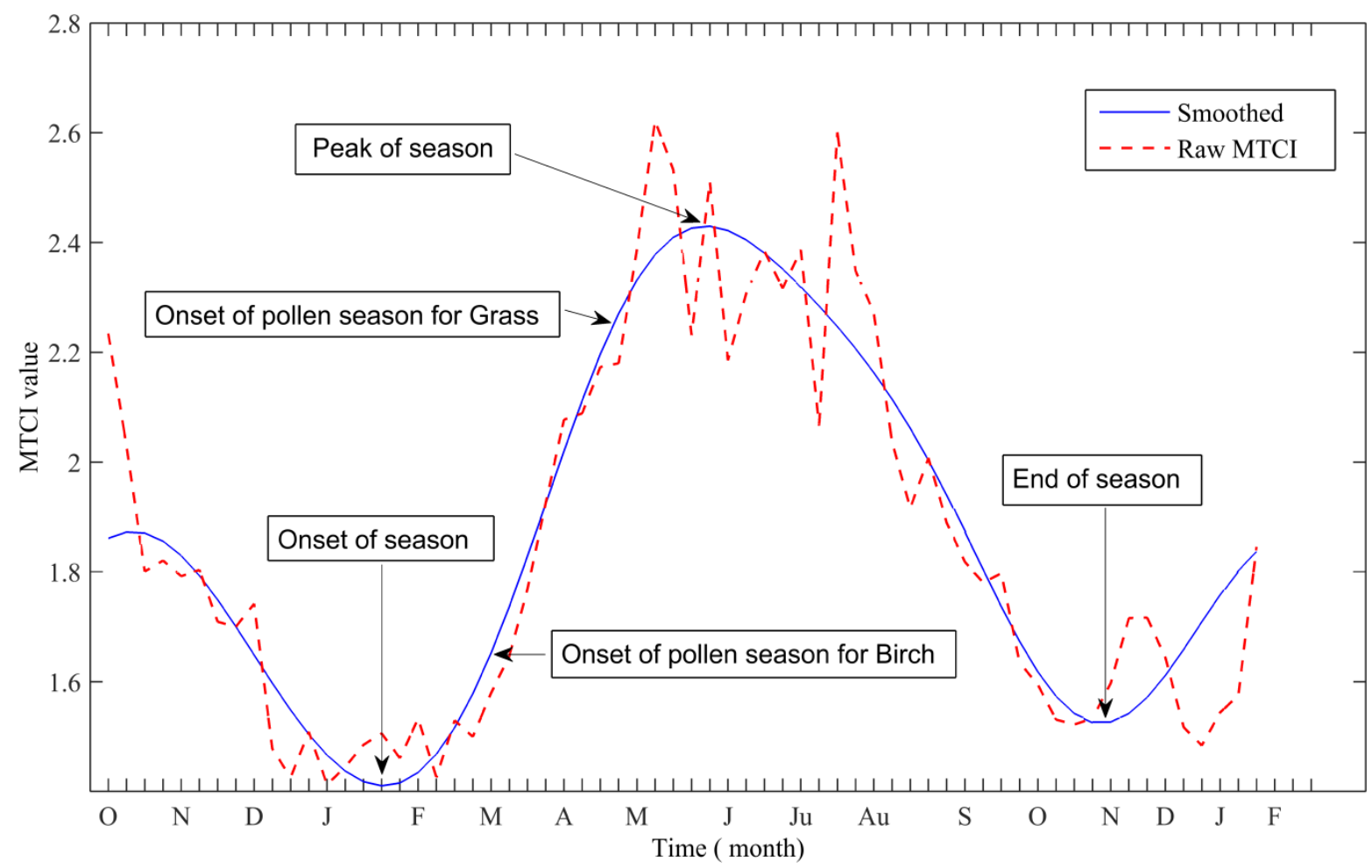

Figure 2. Raw and smoothed MTCI time-series for one pixel for one year and the position of the estimated phenological parameters (i.e. onset of season, onset of pollen season for birch, onset of pollen season for grass, peak of season and end of season).

\subsubsection{Onset of flowering (onset of pollen season)}


Detection of flowering phenophases which occur at the same time or after the start of the season is challenging from time-series of vegetation indices. However, for species where the flowering occurs after the budburst (or development of first leaf), the relative position from the start of growing season could be used to determine the timing of onset of flowering (or the onset of pollen season). This was the rationale behind the study by Karlsen et al., (2009) that provided a satellite-based observation of greenness of woodlands in Norway which was converted into a map that showed local flowering of birch. A similar argument can be used for grass considering the biological fact that the foliage development for most grasses precedes flower blooming. In other words, most grasses start flowering when the foliage development has almost reached a peak (i.e., peak in greenness from the MTCI profile).

After estimating the onset of season and end of season (section 2.2.1), based on the birch and grass flower and foliage development process, a technique was developed to predict the timing of flowering by using (i) the mean temporal profile of the MTCI (i.e. only the pixels belonging to the land cover classes of interest) within a $50 \mathrm{~km}$ buffer of the pollen monitoring station and (ii) onset of pollen season derived from the pollen concentration data for the stations. The total pollen concentration dataset, for eight years and from nine pollen monitoring stations $(n=72)$, was divided randomly into a calibration $(n=54)$ and validation dataset $(n=18)$. For the validation dataset, the randomly selected points were re-selected if there were more than three points per station or zero points per station.

For each station, the timing when the value of MTCI from the start of the season reaches $10 \%$ of the MTCI maximum was determined and this was varied in 5\% increments to define the start of flowering phenophases (start of pollen season). For birch, the timing of flowering (start of pollen season) was defined as the time after the onset of the growing season when the MTCI value reaches $25 \%$ of the maximum. Similarly for grass this was defined as the time when MTCI reached $75 \%$ of the maximum (figure 3 ). The $75 \%$ and $25 \%$ thresholds were selected as they demonstrated smaller standard errors compared to the other thresholds (e.g., $85 \%$ or $35 \%$ of the maximum value of MTCI) (figure 4).

The above technique was applied to each pixel (i.e. $0.0089^{\circ} \sim 1 \mathrm{~km}$ ) for the UK to produce detailed onset of flowering maps of birch and grass across the UK. The maps: (i) an 8-year average (2003-2010) start of season for broadleaf forest and (ii) an 8-year average start of season for grassland, show the timing of flowering that is coincidental with the start of the pollen season for the entire UK. These maps of the start of pollen season were then validated using the validation data set randomly selected from the nine pollen monitoring stations. The 
validation was undertaken based on a correlation analysis (Pearson's correlation) between the corresponding pollen start dates from the validation data $(n=18)$ and mean onset of flowering maps (i.e. within the $50 \mathrm{~km}$ buffer).

Apart from natural annual variation in the start of the pollen season, the transport of pollen and unpredictable weather conditions (e.g. strong gust and storm) also play an important role in affecting the magnitude of the pollen season. The transport of pollen could unpredictably advance the local pollen season at a certain site (e.g. IOWT, London and Belfast). In general, the pollen season estimated from the MTCI data starts 7-13 days earlier than the start dates defined from the pollen concentration data. These discrepancies in the start of the pollen season together with the spatial extent of the points (i.e. the nine sites) resulted in some points appearing as outliers regardless of the fact that there was a general agreement (figure 4). Moreover, errors may be introduced from the buffer size assumption and uncertainty in the MTCI composites, which may need further investigation.

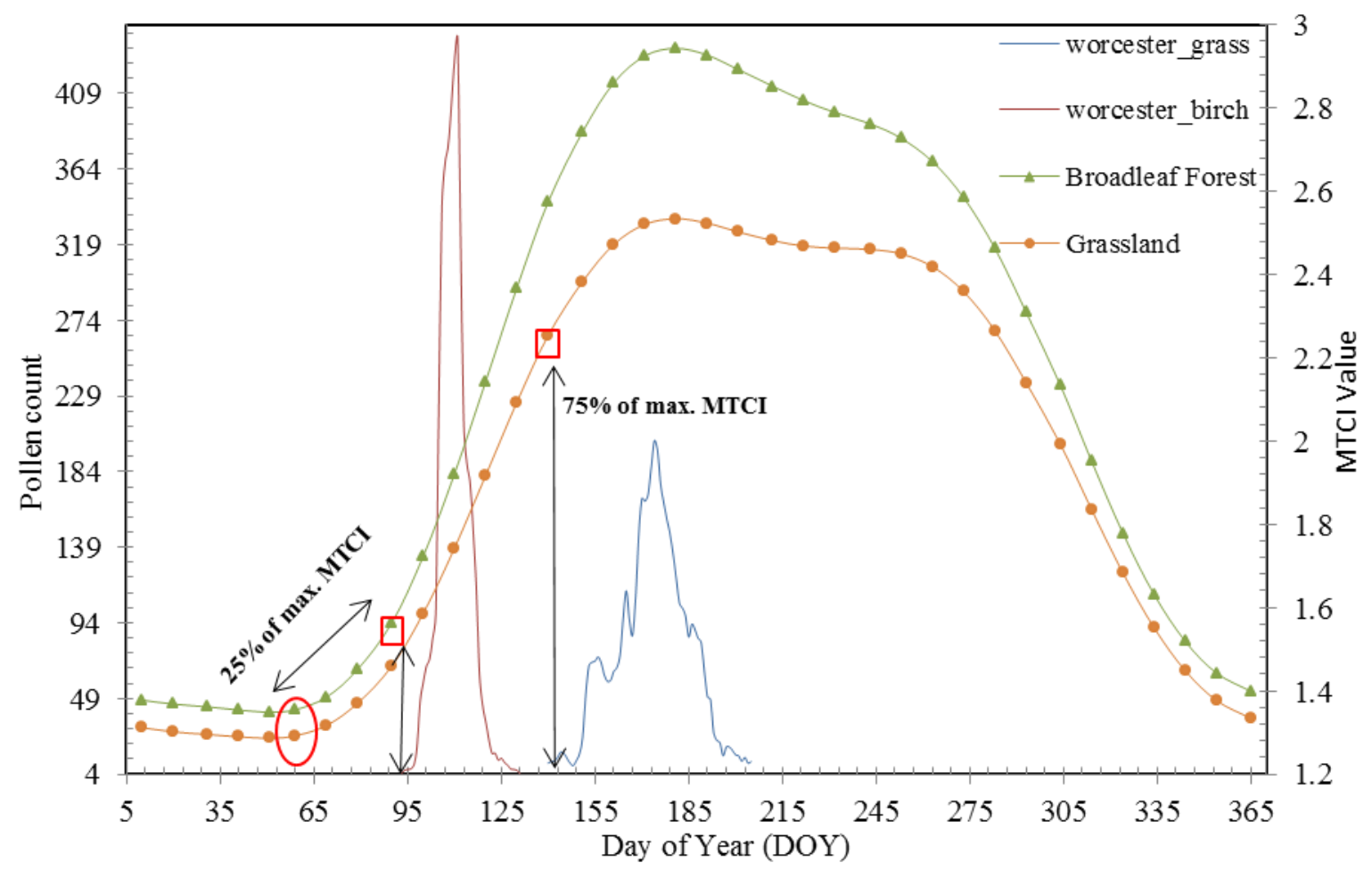

gure 3. Determination of flowering season of birch and grass as $25 \%$ (square shape on the broad leaf forest profile) and $75 \%$ (square shape on the grassland profile) of the maximum value of MTCI, respectively, from the onset of the season (circular shape). The birch and grass pollen profiles (seasons) at Worcester are shown. 

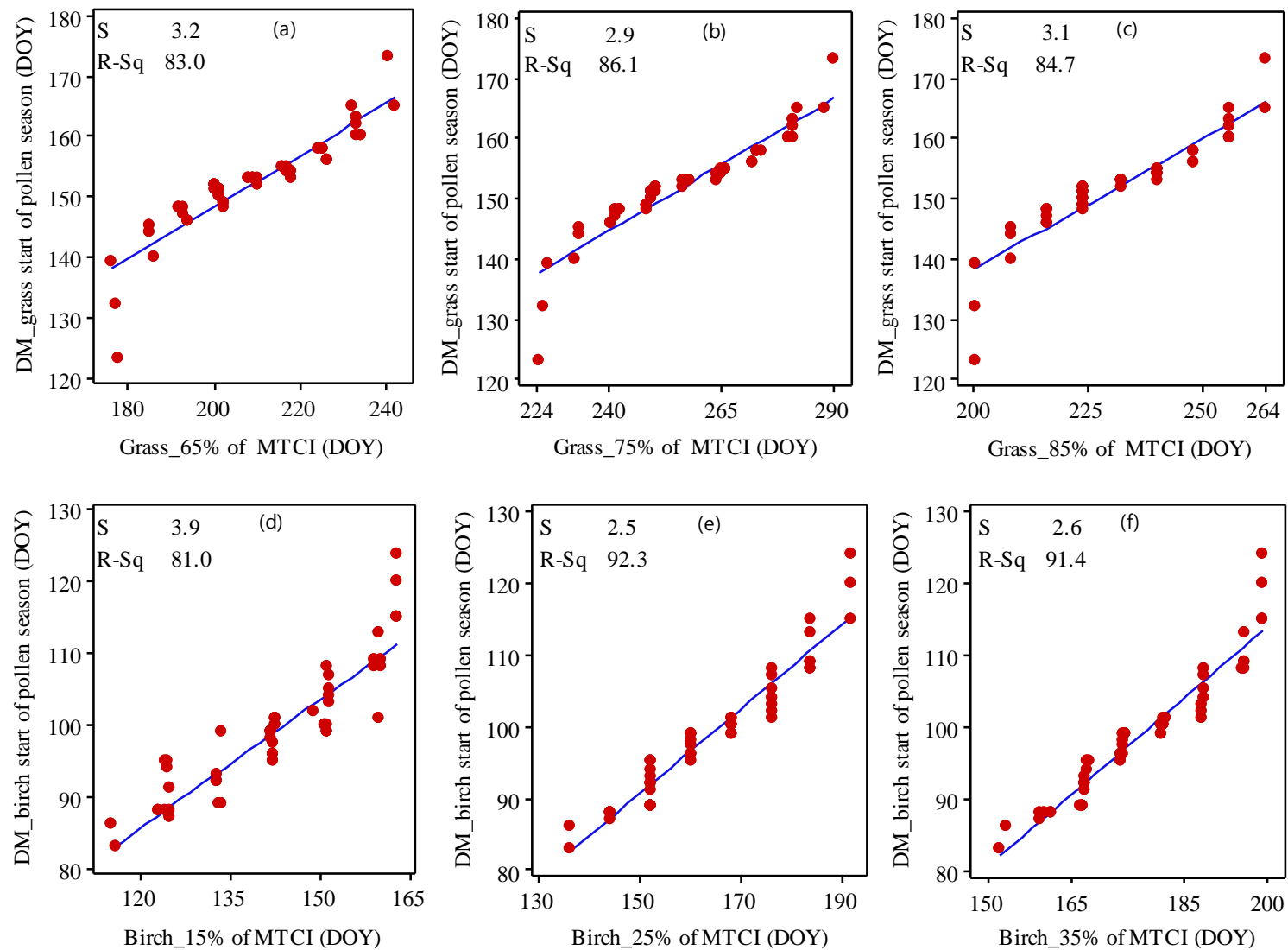

Figure 4. Estimated standard error $(\mathrm{S})$ and coefficient of determination $(\mathrm{R}-\mathrm{Sq})$ derived from the regression line for $(N=54)$ points of the observed start dates of grass (top $(\mathrm{a}, \mathrm{b}, \mathrm{c}))$ and birch (bottom $(\mathrm{d}, \mathrm{e}, \mathrm{f})$ ) seasons from pollen concentration ( $y$-axis) and the estimated start dates from grassland MTCI and broad leaf forest MTCI within a $50 \mathrm{~km}$ buffer around the nine pollen monitoring sites for the period of 8 years.

\subsubsection{Relationship between MTCI derived onset of flowering and start of pollen season from pollen} concentration data

After the onset of flowering for birch and grass was defined from the MTCI time series data within a $50 \mathrm{~km}$ buffer around the stations (section 2.2), a correlation analysis (bivariate Pearson's product-moment correlation) with the start of pollen season (estimated using the three methods defined in section pollen concentration data) was undertaken for the nine stations across the UK. The $50 \mathrm{~km}$ buffer around the stations was used to define the average start dates of flowering season for both birch and grass by averaging only those pixels within the buffer and only those pixels of the land cover classes of relevance (section Landcover data). The start dates of onset of flowering (in Day of Year (DOY)) were correlated with the start dates of grass and birch pollen season (DOY) 
for the period 2003-2010. The correlation analysis was undertaken for each individual year and the average of the 8-year period.

\section{Results}

\subsection{Onset of pollen season from pollen concentration data}

Spatio-temporal variation exists in the start of the grass and birch pollen seasons across all the sites. This spatial variation is due to the relationships between the start dates, defined by the methods, and the latitudes with different regional climates, which influence the phenological development of grass and birch over time. As expected, the start of season, for both grass and birch, is earlier in the south and tends to be later as one moves northwards. For grass, for example, the season starts at 138 DOY (17 May) in the Isle of Wight (IOWT) whereas for Edinburgh the average start of season was detected at 157 DOY (5 June) using the $\Sigma 75$ method. For birch, for example, the season starts in IOWT at 100 DOY (9 April) whereas for Edinburgh the average start date of the season was 107 DOY (16 April) using the $\Sigma 75$ method. For the derivative and $\Sigma 125$ methods a similar south-to-north delay in the start of the season was observed. In Plymouth, the birch season started 9 days earlier than in Invergowrie using the $\Sigma 75$ method. Similarly, the grass pollen season in Plymouth started 13 days earlier than in Invergowrie using the $\Sigma 125$ method. From the three methods used to define the pollen season, the $\Sigma 75$ method estimated the earliest start dates, whereas the $\Sigma 125$ and derivative methods are more similar, especially for the grass season. In contrast, the derivative method estimated the earliest start dates for the birch season compared to the $\Sigma 75$ and $\Sigma 125$ methods. Yet, the three methods equally revealed the south-to-north trend in the start of season (Figure 5).

The difference in days within a pollen monitoring site over time was generally 7-14 days depending on variation in the local weather conditions prior to and during the pollen season. Across all the stations the birch season started earlier than the grass season by an average of 54, 45, 49 days (for the DM, $\Sigma 75$ and $\Sigma 125$ methods, respectively). The length of the birch season across all the stations was on average 21.5 days, whereas for grass it was 56.3 days using the DM method. 


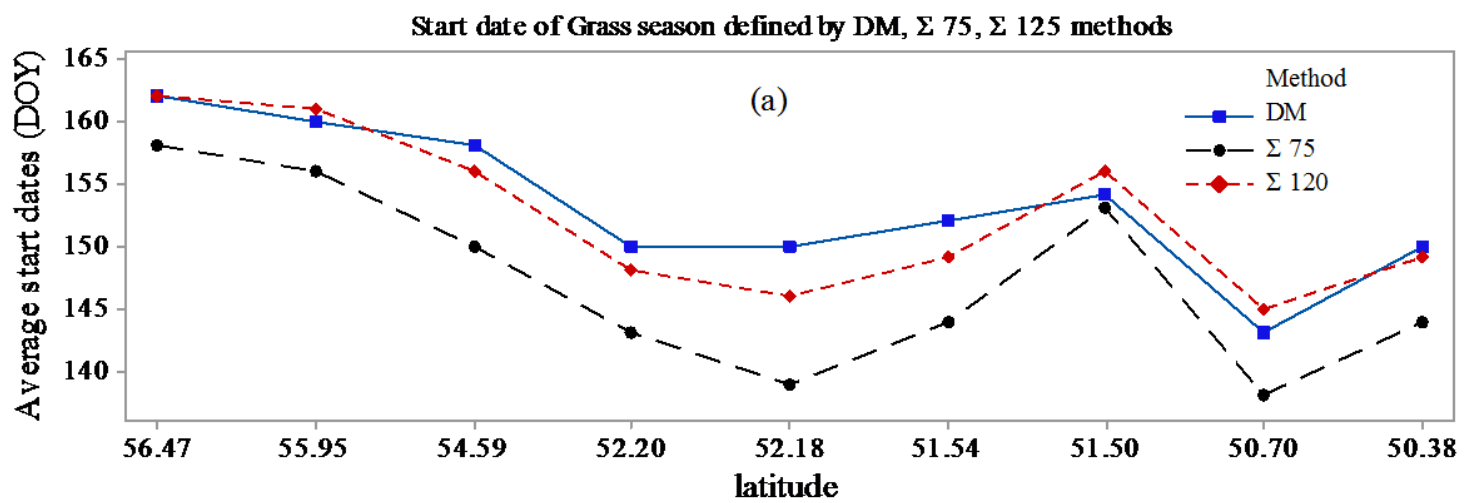

Start date of Birch season defined by DM, $\Sigma 75, \Sigma 125$ methods

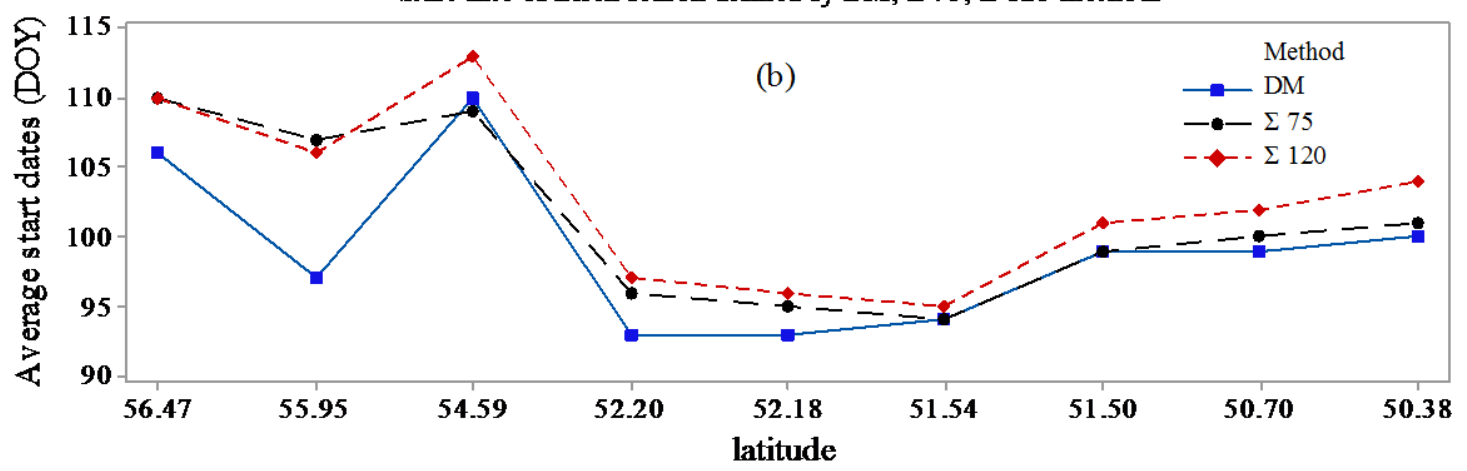

Figure 5. North-to-south trend in the start date of (a) grass and (b) birch pollen seasons estimated by the DM, $\Sigma 75$ and $\Sigma 120$ methods.

\subsection{Validation of onset of flowering (onset of pollen season)}

There was statistically significant agreement between the pollen concentration-derived starting dates (i.e. validation data $(n=18)$ of both the grass and birch seasons defined by the three methods (section pollen concentration data) and the MTCI derived onset of flowering of grass and birch (figure 6) (sections 2.2 to 2.3). MTCI derived onset of flowering for grassland and the start dates of the grass pollen season from the DM method produced the largest statistically significant positive correlation $(r=0.71$; significant at the 0.01 level; St. Error(S) =3.7 days) (Fig.6a). The $\Sigma 75$ method demonstrated a relatively smaller statistically significant positive correlation ( $r=0.49$; significant at the 0.05 level; St. Error(S) $=8.4$ days) (Fig.6b). Similarly for birch, statistically significant correlations were produced between pollen start dates defined by the three methods and the onset of flowering of Broad leaf forest. The correlation was stronger than for grass but produced larger standard errors (for DM $r=0.74$; significant at the 0.01 level; St. Error(S) =7.2 days (Fig.6d): for $\Sigma 75 r=0.74$; significant at the 0.01 level; St. Error(S) $=7$ days (Fig.6e): for $\Sigma 125 r=0.72$; significant at the 0.01 level; St. Error(S) =7.1 days (Fig.6f)) . 

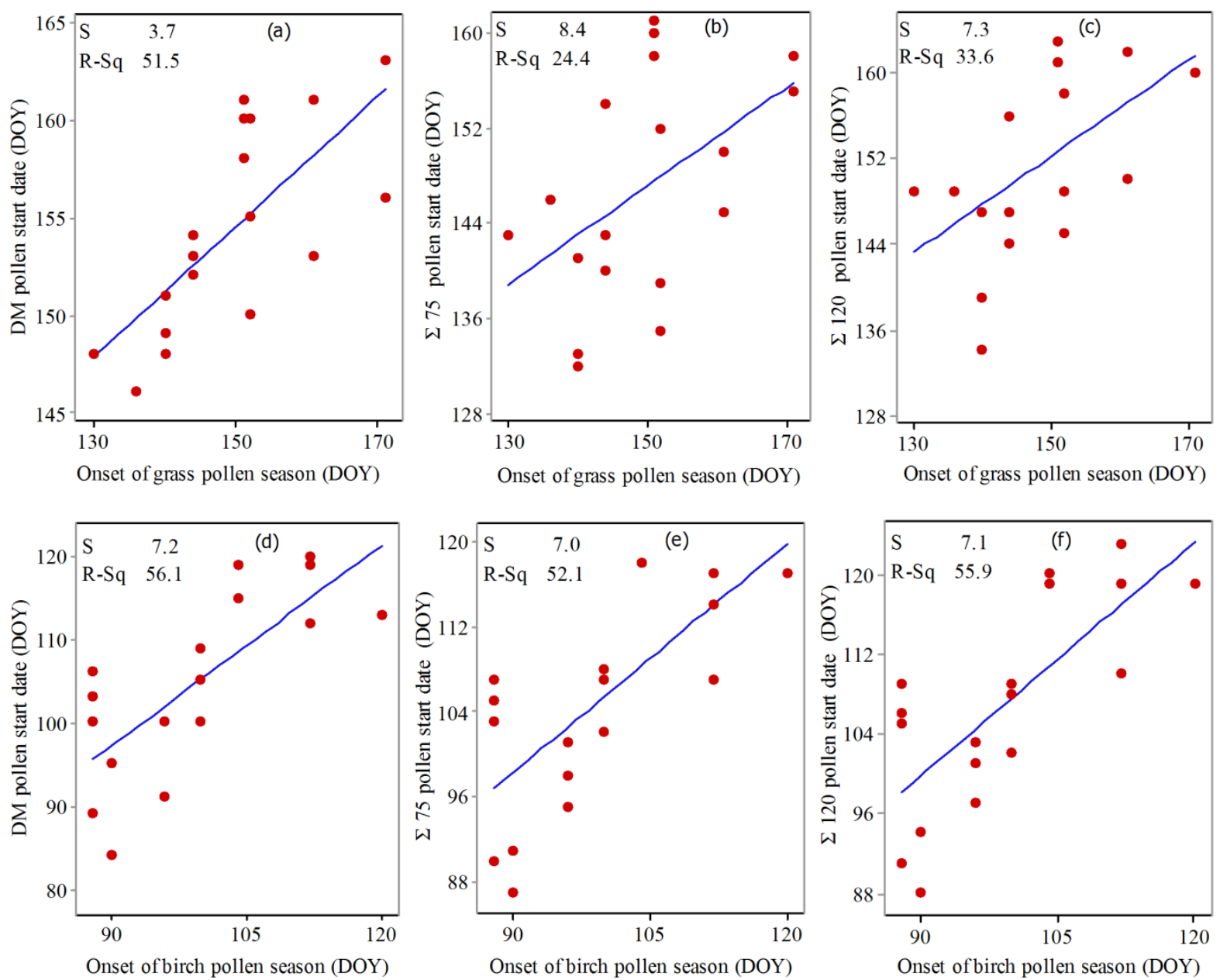

Figure 6. Regression of pollen start date estimated using the (a, d) DM, (b, e) $\Sigma 75$ and (c, f) $\Sigma 125$ methods for (a, $b, c)$ grass pollen and (d, e, f) birch pollen against MTCI start date (onset of pollen season) for (a, b, c) grassland and $(\mathrm{d}, \mathrm{e}, \mathrm{f})$ broadleaf forest within a $50 \mathrm{~km}$ buffer around the nine pollen monitoring sites, for a random selection of 18 of the possible points. Estimated standard error $(\mathrm{S})$ and coefficient of determination $(\mathrm{R}-\mathrm{Sq})$ are shown.

\subsection{Relationship between onset of flowering and pollen concentration data}

The MTCI derived onset of flowering for birch which is based on the Broad leaf forest land cover type demonstrated large significant correlations with the start of pollen season using the three methods (i.e., DM, $\Sigma 75$, 2125). Five out of the eight years produced significant correlations using the DM method with an average $r$ value for the eight years and for the nine sites of $r=0.89$ (significant at the 0.01 level; St. Error=3-4 days). The $\Sigma 75$ and $\Sigma 125$ both demonstrated significant correlations for seven out of eight years for the nine sites with an average $r$-value of $r=0.96$ (significant at the 0.01 level; St. Error=2 days) and $r=0.93$ (significant at the 0.01 level; St. Error=2.6 days), respectively (Tables $2 \& 3$ ). 
For grass, the three methods produced significant correlations for five out of eight years for the DM method and seven out of eight years for the $\Sigma 75$ method and eight out of eight years for the $\Sigma 125$ method for the nine sites across the UK. For the average of eight years the $r$-value for the methods were: for DM the $r=0.83$ (significant at the 0.01 level; St. Error=4 days), for $\Sigma 75$ the $r=0.93$ (significant at the 0.01 level; St. Error=2.7 days), and for $\Sigma 125$ the $r=0.94$ (significant at the 0.01 level; St. Error=2.5 days) (Tables $4 \& 5$ ). The $\Sigma 75$ method for defining the birch pollen season seemed to produce closer agreement with the $25 \%$ maximum MTCI derived onset of flowering date than the other methods. The $\Sigma 125$ method for defining the grass pollen season produced closer agreement with the $75 \%$ maximum MTCI derived onset of flowering date than the DM and $\Sigma 75$ methods.

\subsection{Start of flowering across UK}

The start of flowering pattern for the UK demonstrated variation from year-to-year for the period of 8-years (2003-2010). A clear spatial gradient in the start of flowering for both birch and grass can be observed (Tables

$2 \& 4)$. For example, the flowering dates for birch for northern sites (i.e. Belfast, Edinburgh, and Invergowrie) are 97, 99, and 101, respectively, whereas for the southern sites (i.e. IOWT, Plymouth, London, Worcester, and Cambridge) are 87, 88, 79, 86, 85 DOY, respectively. The London area demonstrated earlier flowering dates in comparison to other sites, probably due to the urban heat island effect. A similar south-to-north trend was also demonstrated by the grass flowering dates (Table 4 and figure 7).

The patterns observed reflect the combination of a patchy landscape, and the varying climate and topography of the UK.

The flowering patterns of both birch and grass reveal more than just a south-to-north trend, and are influenced also by proximity to the coast. The average start of flowering for birch in the southwest, for example, in Plymouth was 88 DOY, yet there were some areas that demonstrated flowering before and after that date depending on the proximity of these pixels to urban areas and the coast. A similar pattern was observed for other sites, for example, for Cardiff and Worcester. In the remote highlands of Scotland (Grampian Mountain areas) early flowering dates of birch can be observed far from residential areas (figure 8). The early flowering is due to the fact that Downy birch is the most abundant birch type, which prefers cooler and wetter environments (UK Forestry Commission (http://www.forestry.gov.uk)). 

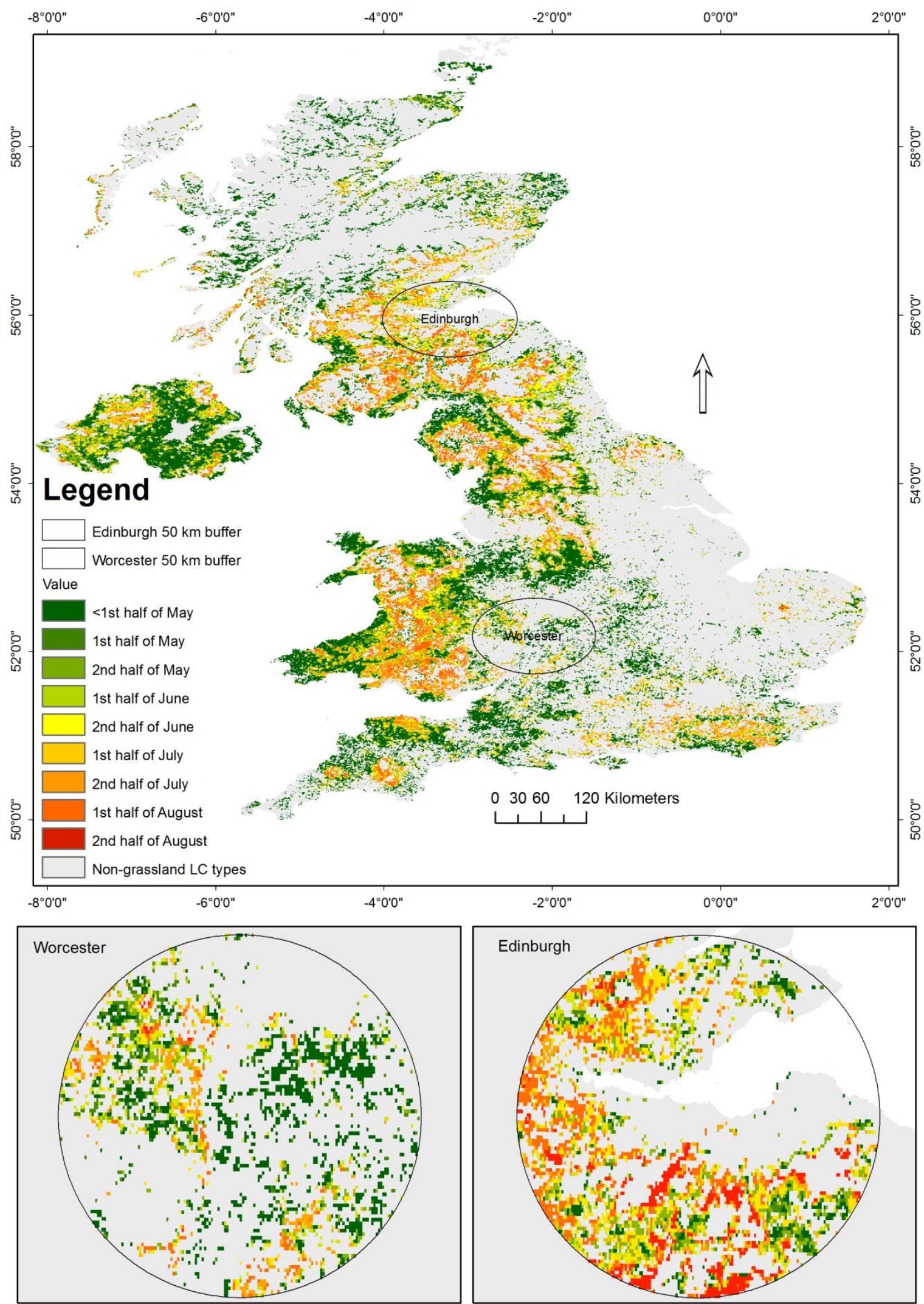

Figure 7. 8-year average MTCI-based map of onset of flowering of grassland as a source of grass pollen. The map depicts the spatial variation in the onset of flowering coincidental with the start of pollen season. 

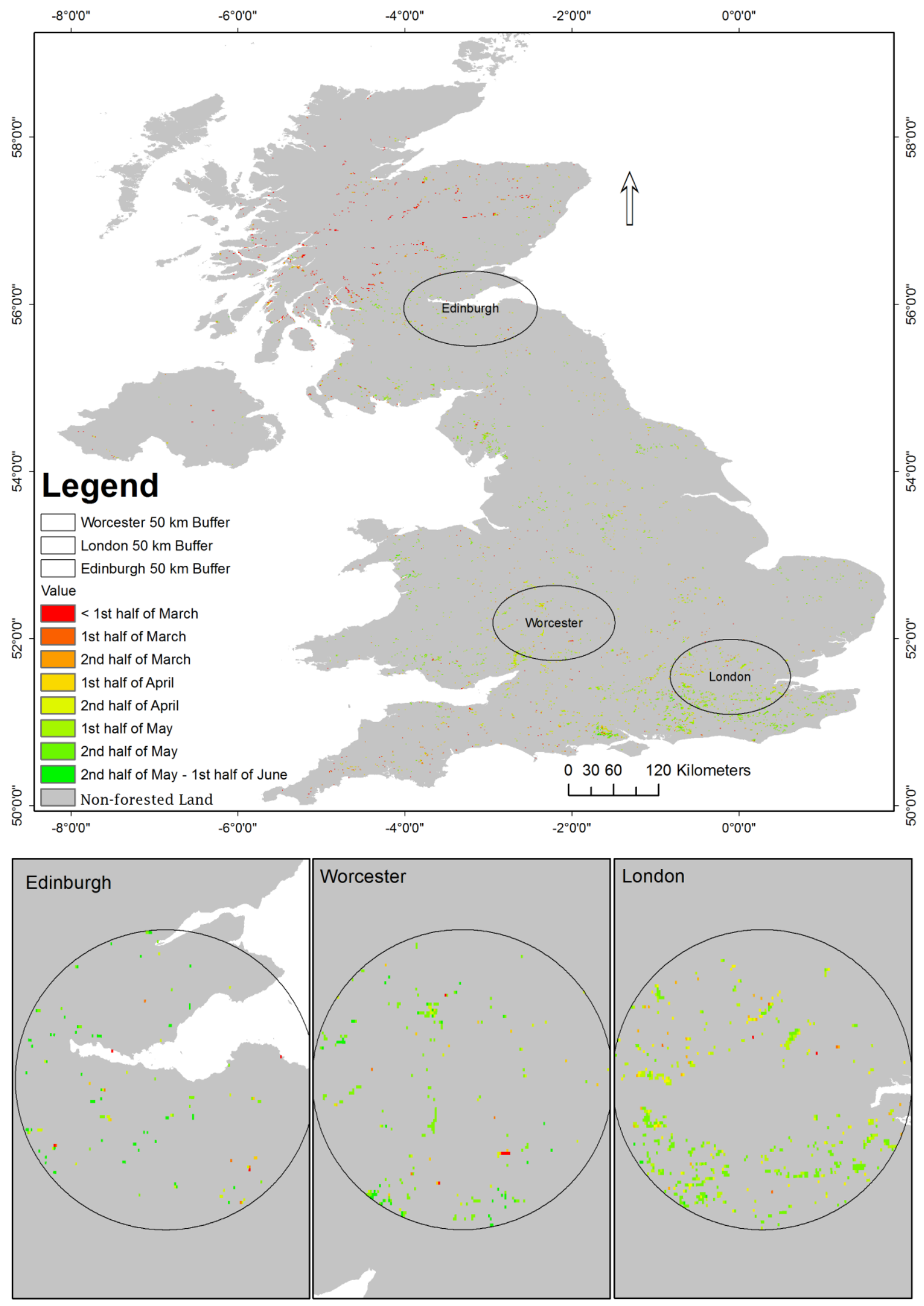

Figure 8. 8-year average MTCI-based onset flowering map of broadleaf forest as a source of birch pollen. The map depicts the spatial variation in the onset of flowering coincidental with the start of the pollen season. 


\section{Discussion}

\subsection{Onset of pollen season from pollen concentration data}

Employing various methods, this research quantified the spatial and temporal variation in the start of the grass and birch pollen seasons in the UK. Generally, as expected the pollen seasons start earlier in the south of the UK compared to the north. More importantly, the research quantified the expected local values in the absolute sense and their relative variation across space and time. The average of the 8-year time-series shows that the birch pollen season in Plymouth starts ( $(275) 9$ days earlier than Invergowrie and 6 days earlier than Edinburgh. Similarly, the grass pollen season in Plymouth starts $(\Sigma 125) 13$ days earlier than Invergowrie and 12 days earlier than Edinburgh. These results concur with previous studies focused on regional variation in pollen season characteristics (Corden et al., 2000; Emberlin et al., 2000; Sánchez Mesa et al., 2003). Climate variation across the UK causes spatial variation in the timing of the onset of the pollen seasons. Increases in temperature in the spring influence phenological development, including the timing of flowering or anthesis prior to the main pollen season (Emberlin et al., 1999). The earlier the start of flowering, the earlier the end of the annual life cycle of grass and birch, but not necessarily the end of the pollen season due to the possibility of pollen being transported in the air (birch) and a large number of species (grass)..

Using the pollen data we were able to estimate the average length of the pollen season across all stations as 21.5 days for birch, and 56.3 days for grass in the UK. The length of pollen seasons is generally dependent on factors that influence the phenological development of vegetation, and the abundance and dispersal of pollen such as local vegetation type, altitude, land use and climate (Emberlin et al., 2000; Green et al., 2004; Jato et al., 2009; Sabariego et al., 2011). Furthermore, the length of pollen season for grasses also depends on the continuous pollen load to the pollen profile from a high number of grasses species that have different flowering dates. In contrast, the length of birch pollen season is more dependent on the transport pollen.

The allergenicity of birch and grass is related to the relative amount of allergen and allergenic extracts in the pollen grains. Quantification of the amount of allergen on pollen is challenging due to its variability in space and time (Buters et al., 2012). Therefore, measurement is usually done through pollen grain count sampling in a cubic metre of air. This is done by employing a special motor to suck in the pollen from the atmosphere, such as a volumetric trap, and then counting and identifying allergenic pollen under a microscope. This research and 
most published aerobiology researches are based on the collecting and analysing of physically intact pollen grains from the atmosphere. The complex chemistry and physics of atmospheric composition, in particular in recent decades due to several kinds of pollutants (particulate matter), have led to allergic particles being available in the atmosphere independently of pollen. Thus, the effects of meteorology in the transport of pollen is not only limited to the physical transport processes and conditions for pollen production and release, but also may play a significant alteration in the pollen size distribution. Taylor et al., (2004) reported that birch pollen would rupture in high humidity and moisture. The size of the ruptured pollen grains ranged from $30 \mathrm{~nm}$ to 4 microns, much smaller than the range of typical allergenic plant species pollen. Furthermore, the origin of the allergic particles may be from plant material or could result from the cross-reactivity between atmospheric pollutants. These tiny allergic particles contribute to the allergic symptoms in particular during the early and late pollen seasons (Spieksma et al., 1989). Furthermore, Agarwal et al., (1981) reported that pollen counts do not always correlate with the allergen load of the atmosphere, which suggest that the durataion of pollen season may not equate to the period of allergenicity. Therefore, it is important to further investigate and understand in detail the pattern and the significance of the tiny allergic particles (i.e., Micronics), their variation through the pollen season and their relationship with hay fever symptoms.

4.2 Relationship between MTCI-based onset of flowering and start of pollen season from pollen concentration data

The simple mathematical technique used to define the onset of flowering of birch and grass was based on phenological development, especially the leaf emergence phenophase temporal profile, measured indirectly using a satellite sensor chlorophyll index (i.e. MTCI). The temporal profile provides information on the timing of flowering which is coincidental with pollen release and hence the pollen season and the emergence of hay fever symptoms. Moreover, the MTCI-based prediction of flowering phenophase is effectively a spatial representation of birch and grass pollen sources tagged with the timing of a biological event (i.e. flowering phenophase) which varies from year-to-year depending on environmental conditions, especially temperature, in the UK. The spatial representation of birch and grass sources is at the $1 \mathrm{~km}$ pixel ground resolution for the whole UK; this information is extensive in comparison to the limited number of pollen monitoring sites across the country. Importantly, the combination of the MTCI-predicted timing of flowering at the 'source' areas 
together with the ground-based pollen profile at the 'sink' or receptor has the potential to increase our understanding of local variation in pollen, local start date and length of pollen season.

The flowering phenophase used in this study is a surrogate indicator for the onset of pollen season. Thus, they can be used interchangeably for species producing allergens during flowering. The greenness profile of the vegetation canopy and the date of flowering (or onset of pollen season) for the two species (grass and birch) was measured from the MTCI time series, determined as a relative position after the start of the growing season. For the two species investigated here the start of flowering and release of pollen coincide and due to the biological development cycle of these species, the flowering phenophase starts after the vegetation canopy has reached a certain level of greenness. However, this method may not be applicable to detect the start of pollen season for species where pollen are released through different mechanisms (For example, ragweed usually pollinate in late August where the greenness profile is declining).

This research found statistically significant positive correlations between the pollen concentration-derived starting dates of the pollen seasons of both birch and grass, and the MTCI-based start dates, indicating the suitability of using the MTCI to predict the start of pollen season indirectly, potentially in combination with relevant weather parameters, for example, temperature and precipitation. This result supports the study by Karlsen et al., (2009) which used a threshold of MODIS NDVI to define the start of the birch pollen season and related it with pollen season start date. The slightly smaller correlation coefficients for grass are likely related to the larger number of grass species in the UK and, thus, the various physiological differences in leaf development.

\section{3 spatial variation in birch and grass flowering across the UK}

The MTCI-based flowering phenophases of birch and grass estimated in this research vary spatially and temporally (2003- 2010). The spatio-temporal variation is determined by weather conditions during and preceding a growing season (Sánchez Mesa et al., 2003). Apart from spatio-temporal variation, local variation (i.e. pixel-based) was also noticed near residential areas, most likely due to the influence of the urban heat island on phenological development. Moreover, land cover type management strategy (i.e. for grass) also affects pollen concentration and thus annual pollen catch at the 'sink'.

Both birch and grass MTCI-based flowering maps showed a south-to-north spatial pattern and, hence, produced large positive correlations with the corresponding dates of the pollen monitoring sites. Yet, a smooth gradient 
from south-centre-north is not obvious due to the uneven distribution of grass and birch land cover types across the UK and influence of microclimate. For example, with regard to the birch distribution on the IOWT, the upper southern region has only a few pixels whereas many pixels exist near London. Furthermore, the $50 \mathrm{~km}$ buffer average of the dates of flowering is more realistic in terms of spatial representation of the dates of flowering where the buffer fully intersects with the cover types, for example, in Worcester and London.

Currently, the Met Office pollen forecast in the UK (http://www.metoffice.gov.uk/health/public/pollen-forecast) is based mainly on the pollen concentrations being collected at various stations for various regions across the country linked to weather conditions. The pollen monitoring stations are distributed based on regional climate variation. The pollen forecast for each region is based on pollen concentrations from the pollen monitoring stations and systematic evaluation of weather forecasts and pollen concentrations from previous years. The produced link between the pollen data and relevant weather variable or predictors is mostly a statistical one. The MTCI-based onset of flowering maps of birch and grass (which present the average 8-year variation for the UK) together with the pollen forecast from the Met Office provide more accurate information to allergy sufferers and such maps could be used as (i) a reference for new pollen monitoring stations to be established in terms of spatial representation (Karlsen et al., 2009), and (ii) they could provide up-to-date geographically coverage of the source distribution. Thus, averaging the results over many years for onset of flowering is necessary to develop a reference map of the mean timing of onset of birch flowering, given the large variation in the timing of the flowering from year-to-year (Karlsen et al., 2009).

Long distance transport of pollen, especially birch pollen that may advance the local pollen season, is well documented ( Oikonen et al., 2005; Ranta et al., 2006; Mahura et al., 2007; Skjøth et al., 2008a, 2008b). The MTCI-based prediction of birch flowering does not necessarily reflect the experienced local timing of the pollen season. The transport of pollen in the UK may vary from region-to-region, for example, as a function of topography. England consists mostly of lowland terrain, with upland or mountainous terrain only found northwest of the Tees-Exe line (an imaginary line dividing the UK into lowland and upland regions, Figure 1), whereas the rest of the country (i.e., Scotland, Wales, and Northern Ireland) has more mountainous topography. Thus, England is more likely to be affected by regional transport of pollen than the rest of the country. 
Smith et al., (2005b) reported grass pollen in the UK (i.e. in Worcester city: Midland of England) that originated from continental Europe. Considering the size of the buffer (i.e. $50 \mathrm{~km}$ buffer around the pollen monitoring sites) used in this research, the recorded large correlation between MTCI-based date of onset of flowering of birch and grass and the start dates of their corresponding pollen seasons defined using three threshold methods (Tables 1 \& 3) raises the question of how significant is the role of pollen transport in influencing the local start of pollen season in the UK. Furthermore, the buffer size of $50 \mathrm{~km}$ may not be optimal in terms of adequate representation of the aeroallergen sources around the pollen monitoring stations and this, along with the temporal uncertainty from the MTCI 8-day composites may introduces uncertainties in the predictions of the start of the growing season and therefore, the onset of the pollen season.

\section{Conclusion}

The combination of predicted phenophases for key aeroallergens at the 'source' areas together with measured pollen levels at the 'sink' or receptor has the potential to improve pollen forecasting and increase our understanding of local variation in pollen distribution. In this study, time-series of MERIS Terrestrial Chlorophyll Index (MTCI) data were used to predict two key phenological variables: the start of season and peak of the pollen season for birch and grass across the UK. A technique was also developed to estimate the flowering phenophase of birch and grass from the MTCI time-series. For birch, the timing of flowering was defined as the time after the start of the growing season when the MTCI value reached $25 \%$ of the maximum value for the season. Similarly, for grass this was defined as the time when the MTCI value reached $75 \%$ of the maximum value.

The predicted pollen release dates from MTCI were validated with data from nine pollen monitoring stations from across the UK. Statistically significant positive correlations between the pollen concentration-derived starting dates of the pollen seasons of both birch and grass, and the MTCI-based start dates, indicate the suitability of using the MTCI to predict the start of pollen season indirectly, potentially in combination with relevant weather parameters.

The technique was applied to produce detailed maps for the flowering of birch and grass across the UK for each of the years from 2003 to 2010. The results demonstrate that the remote sensing-based maps of flowering onset of birch and grass together with the pollen forecast from the Meteorology Office and National Pollen and 
Aerobiology Research Unit (NPARU) can be used to develop more accurate and timely information to pollen allergy sufferers in the UK.

Although high positive correlations were observed in this research, suggesting the potential of satellite sensor data to predict the date of pollen release, it would be desirable to account for the known physical pollen transport mechanisms when mapping local pollen concentration, particularly for allergy sufferers who, in general, experience pollen at sink (i.e. pollen sites which, in most cases, are located in urban areas), not at source (i.e. cover classes identified as sources of pollen emission). The use of phenological models together with weather parameters and atmospheric transport model could help to address this issue and, thus, increase the correlations reported here.

As far as we are aware, this is the first time that remote sensing has been used to estimate the phenological phases related to pollen release in the UK, and worldwide such investigations are rare.

\section{Acknowledgements}

The authors would like to thank the National Pollen and Aerobiology Research Unit (NPARU) of the University of Worcester for providing pollen concentration data. We are also grateful to: (i) The Queen's University Belfast pollen monitoring group, coordinated by $\mathrm{Dr}$ Chris Hunt for collecting and compiling the pollen concentrationdata at the Belfast site, (ii) Miss Ursula Allitt for collecting and compiling pollen concentration data at the Cambridge site, (iii) the Cardiff School of Health Sciences, Cardiff Metropolitan University for collecting and compiling pollen concentration data at the Cardiff site, (iv) Peter Comber and The David Hide Asthma and Allergy Research Centre, St Mary's Hospital, Newport, Isle of Wight, PO30 5TG for collecting and compiling pollen concentration data at the Isle of Wight site, and (v) Dr Gavin Ramsay for collecting and compiling pollen concentration data at the Invergowrie (near Dundee) site. MTCI data were provided courtesy of the NERC Earth Observation Data Centre (NEODC). The authors thank ESA who provided the original data and Airbus Defence and Space who processed the data. The authors are grateful to the Kurdistan Regional Government (KRG) for providing funding through a PhD studentship to NK. Last but not least PMA is grateful to the University of Utrecht for supporting him with The Belle van Zuylen Chair. 


\section{References}

Aas K, Allergy UIo, van Moerbeke D, Åberg N, Bachert C., 1997. European allergy white paper: Allergic diseases as a public health problem in europe:UCB Institute of allergy.

Adams-Groom B, Emberlin J, Corden J, Millington W \& Mullins J., 2000 . Predicting the start of the birch pollen season at London, Derby and Cardiff, United Kingdom, using a multiple regression model, based on data from 1987 to 1997. Aerobiologia 18(2): 117-123

Agarwal, M. K., Yunginger, J. W., Swanson, M. C., \& Reed, C. E., 1981 . An immunochemical method to measure atmospheric allergens. Journal of Allergy and Clinical Immunology 68: 194-200.

Atkinson, P.M., Jeganathan, C., Dash, J., \& Atzberger, C., 2012 . Inter-comparison of four models for smoothing satellite sensor time-series data to estimate vegetation phenology. Remote Sensing of Environment, 123, 400-417

BAF, 1995 . Airborne pollen and spores: A guide to trapping and counting. Aylesford: British Aerobiology Federation 1995. ISBN 0-9525617-0-0

Beurs de and Henebry, 2010. Spatio-Temporal Statistical Methods for Modelling Land Surface Phenology. In I.L. Hudson \& M.R. Keatley (Eds.), Phenological Research (pp. 177-208): Springer Netherlands Boyd, D.S., Almond, S., Dash, J., Curran, P.J., \& Hill, R.A., 2011. Phenology of vegetation in Southern England from Envisat MERIS terrestrial chlorophyll index (MTCI) data. International Journal of Remote Sensing, 32, 8421-8447

Bousquet, P.J., Chinn, S., Janson, C., Kogevinas, M., Burney, P., \& Jarvis, D., 2007. Geographical variation in the prevalence of positive skin tests to environmental aeroallergens in the European Community Respiratory Health Survey I. Allergy, 62, 301-309

Bousquet, J., Khaltaev, N., Cruz, A. A., Denburg, J., Fokkens, W. J., Togias, A., et al., 2008. Allergic Rhinitis and its Impact on Asthma (ARIA) 2008 update (in collaboration with the World Health Organization, GA(2)LEN and AllerGen). Allergy, 63 Suppl 86: 8-160

Burr, M.L., 1999. Grass pollen: trends and predictions. Clin Exp Allergy, 29, 735-738 
Buters, J. T. M., Thibaudon, M., Smith, M., Kennedy, R., Rantio-Lehtimaki, A., Albertini, R., et al., 2012. Release of Bet v 1 from birch pollen from 5 European countries. Results from the HIALINE study. Atmospheric Environment 55: 496-505.

Chen, J.M., Feng, D., \& Mingzhen, C., 2006. Locally adjusted cubic-spline capping for reconstructing seasonal trajectories of a satellite-derived surface parameter. Geoscience and Remote Sensing, IEEE Transactions on, 44, 2230-2238

Chuine and Belmonte, 2004. Improving prophylaxis for pollen allergies: Predicting the time course of the pollen load of the atmosphere of major allergenic plants in France and Spain. Grana, 43, 65-80

Corden, J., Millington, W., Bailey, J., Brookes, M., Caulton, E., Emberlin, J., Mullins, J., Simpson, C., \& Wood, A., 2000. UK regional variations in Betula pollen (1993-1997). Aerobiologia, 16, 227-232

D'Amato G., 2000. Urban air pollution and plant-derived respiratory allergy. Clinical \& Experimental Allergy, $30,628-636$

Dash, J., 2010. Algorithm Theoretical Basis Document for OLCI Terrestrial Chlorophyll Index (OTCI). In (p. 21 ). Southampton: University of Southampton

Dash, J., \& Curran, P.J.,2004. The MERIS terrestrial chlorophyll index. International Journal of Remote Sensing, 25, 5403-5413

Dash, J., Curran, P.J. \& Foody, G. M., 2008. Remote sensing of terrestrial chlorophyll content. In: Cracknell, A.P., Krapivin, V.F. and Varotsos, C.A., eds. Global Climatology and Ecodynamics: Anthropogenic Changes to Planet Earth. Berlin, Heidelberg: Springer Berlin Heidelberg, pp. 77-105.

Dash, J., Jeganathan, C., \& Atkinson, P.M., 2010. The use of MERIS Terrestrial Chlorophyll Index to study spatio-temporal variation in vegetation phenology over India. Remote Sensing of Environment, 114, $1388-1402$

Driessen, M.N.B.M., van Herpen, R.M.A., \& Smithuis, L.O.M.J., 1990. Prediction of the start of the grass pollen season for the southern part of the Netherlands. Grana, 29, $79-86$

Emberlin, J., Savage, M., \& Woodman, R.,1993. Annual variations in the concentrations of Betula pollen in the London area, 1961-1990. Grana 32: 359-363.

Emberlin, J., Mullins, J., Corden, J., Millington, W., Brooke, M., Savage, M., 1999. Regional variations in grass pollen seasons in the UK, long-term trends and forecast models. Clinical \& Experimental Allergy, 29, $347-356$ 
Emberlin, J., 2009. Grass, Tree, and Weed Pollen. Allergy and Allergic Diseases (pp. 942-962): WileyBlackwell

Emberlin, J., Jaeger, S., Dominguez-Vilches, E., Soldevilla, C., Hodal, L., Mandrioli, P., Lehtimäki, A., Savage, M., Spieksma, F., \& Bartlett, C., 2000. Temporal and geographical variations in grass pollen seasons in areas of western Europe: an analysis of season dates at sites of the European pollen information system. Aerobiologia, 16, 373-379

Emberlin, J., Mullins, J., Corden, J., Millington, W., Brooke, M., Savage, M., \& Jones, S., 1997. The trend to earlier birch pollen seasons in the U.K.: A biotic response to changes in weather conditions? Grana, 36, $29-33$

Emberlin, J., Smith, M., Close, R. and Adams-Groom, B., 2007. Changes in the pollen seasons of the early flowering trees Alnus spp. and Corylus spp. in Worcester United Kingdom 1996-2005. Int J Biometeorol 51, 181-191

Estrella, N., Menzel, A., Krämer, U., \& Behrendt, H., 2006. Integration of flowering dates in phenology and pollen counts in aerobiology: analysis of their spatial and temporal coherence in Germany (19921999). International Journal of Biometeorology, 51, 49-59

Fisher, J.I., \& Mustard, J.F., 2007. Cross-scalar satellite phenology from ground, Landsat, and MODIS data. Remote Sensing of Environment, 109, 261-273

Galán, C., Emberlin, J., Domínguez, E., Bryant, R.H., \& Villamandos, F., 1995., A Comparative Analysis of Daily Variations in the Gramineae Pollen Counts at Córdoba, Spain and London, UK. Grana, 34, 189198

García-Mozo, H., Galán, C., Belmonte, J., Bermejo, D., Candau, P., Díaz de la Guardia, C., Elvira, B., Gutiérrez, M., Jato, V., Silva, I., Trigo, M.M., Valencia, R., \& Chuine, I., 2009. Predicting the start and peak dates of the Poaceae pollen season in Spain using process-based models. Agricultural and Forest Meteorology, 149, 256-262

Geerken, R., Zaitchik, B., \& Evans, J.P., 2005. Classifying rangeland vegetation type and coverage from NDVI time series using Fourier Filtered Cycle Similarity. International Journal of Remote Sensing, 26, 55355554 
Green, B.J., Dettmann, M., Yli-Panula, E., Rutherford, S., \& Simpson, R., 2004. Atmospheric Poaceae pollen frequencies and associations with meteorological parameters in Brisbane, Australia: a 5-year record, 1994-1999. Int J Biometeorol, 48, 172-178

Hay, S.I., Tatem, A.J., Graham, A.J., Goetz, S.J., \& Rogers, D.J., 2006. Global Environmental Data for Mapping Infectious Disease Distribution. In A.G. Simon I. Hay \& J.R. David (Eds.), Advances in Parasitology (pp. 37-77): Academic Press

Heumann, B.W., Seaquist, J.W., Eklundh, L., \& Jönsson, P., 2007. AVHRR derived phenological change in the Sahel and Soudan, Africa, 1982-2005. Remote Sensing of Environment, 108, 385-392

Hirst, J.M., 1952. An automatic volumetric spore trap. Annals of Applied Biology, 39, 257-265

Hird, J.N., \& McDermid, G.J., 2009. Noise reduction of NDVI time series: An empirical comparison of selected techniques. Remote Sensing of Environment, 113, 248-258

Hogda, K.A., Karlsen, S.R., Solheim, I., Tommervik, H., \& Ramfjord, H., 2002. The start dates of birch pollen seasons in Fennoscandia studied by NOAA AVHRR NDVI data. In, Geoscience and Remote Sensing Symposium, 2002. IGARSS '02. 2002 IEEE International (pp. 3299-3301 vol.3296)

Jakubauskas, M.E., Legates, D. R., \& Kastens, J. H., 2001. Harmonic analysis of timeseries AVHRR NDVI data. Photogrammetric Engineering and Remote Sensing, 67, 461-470

Jato, V., Méndez, J., Rodríguez-Rajo, J., \& Seijo, C., 2002. The relationship between the flowering phenophase and airborne pollen of birch (Betula); in galicia (N.W. spain). Aerobiologia, 18, 55-64

Jato, V., Rodríguez-Rajo, F., Seijo, M., \& Aira, M., 2009. Poaceae pollen in Galicia (N.W. Spain): characterisation and recent trends in atmospheric pollen season. International Journal of Biometeorology, 53, 333-344

Jeganathan, C., Dash, J., \& Atkinson, P.M., 2014. Remotely sensed trends in the phenology of northern high latitude terrestrial vegetation, controlling for land cover change and vegetation type. Remote Sensing of Environment, 143, 154-170

Jönsson, P., \& Eklundh, L., 2002. Seasonality extraction by function fitting to time-series of satellite sensor data. Geoscience and Remote Sensing, IEEE Transactions on, 40, 1824-1832

Jönsson, P., \& Eklundh, L., 2004. TIMESAT — a program for analyzing time-series of satellite sensor data. Computers \& Geosciences, 30, 833-845

Karlsen, S.R., Ramfjord, H., Høgda, K.A., Johansen, B., Danks, F.S., \& Brobakk, T.E., 2009. A satellite-based map of onset of birch (Betula) flowering in Norway. Aerobiologia, 25, 15-25 
Khwarahm, N., Dash, J., Atkinson, P., Newnham, R.M., Skjøth, C.A., Adams-Groom, B., Caulton, E., \& Head, K., 2014. Exploring the spatio-temporal relationship between two key aeroallergens and meteorological variables in the United Kingdom. International Journal of Biometeorology, 1-17

Laaidi, K., 2001. Predicting days of high allergenic risk during Betula pollination using weather types. Int J Biometeorol, 45, 124-132

Linkosalo, T., 1999. Regularities and patterns in the spring phenology of some boreal trees. Silva Fennica, 33 , $237-245$

Linkosalo, T., 2000. Mutual regularity of spring phenology of some boreal tree species: predicting with other species and phenological models. Canadian Journal of Forest Research, 30, 667-673

Lloyd, D., 1990. A phenological classification of terrestrial vegetation cover using shortwave vegetation index imagery. International Journal of Remote Sensing, 11, 2269-2279

Los, S.O., Pollack, N.H., Parris, M.T., Collatz, G.J., Tucker, C.J., Sellers, P.J., Malmström, C.M., DeFries, R.S., Bounoua, L., \& Dazlich, D.A., 2000. A Global 9-yr Biophysical Land Surface Dataset from NOAA AVHRR Data. Journal of Hydrometeorology, 1, 183-199

Luvall, J.C., Sprigg, W., Levetin, E., Huete, A., Nickovic, S., Pejanovic, G., Van de Water, P., Myers, O., Budge, A., Crimmins, T., Krapfl, H., \& Zelicoff, A., 2011. Use of MODIS Satellite Images and an Atmospheric Dust Transport Model To Evaluate Juniperus Spp. Pollen Phenology and Dispersal to Support Public Health Alerts. Journal of Allergy and Clinical Immunology, 127, Ab19-Ab19

Mahura, A., Korsholm, U., Baklanov, A., \& Rasmussen, A., 2007. Elevated birch pollen episodes in Denmark: contributions from remote sources. Aerobiologia, 23, 171-179

Newnham, R.M., Sparks, T.H., Skjøth, C.A., Head, K., Adams-Groom, B., \& Smith, M., 2013. Pollen season and climate: Is the timing of birch pollen release in the UK approaching its limit? International Journal of Biometeorology, 57, 391-400

Neil, K. and Wu, J., 2006. Effects of urbanization on plant flowering phenology: A review. Urban Ecosyst $9: 243-257$

Oikonen, M., Hicks, S., Heino, S., Rantio, L., auml, \& ki, A., 2005. The start of the birch pollen season in Finnish Lapland: separating non-local from local birch pollen and the implication for allergy sufferers. Grana, 44, 181-186

Olsson, L., Eklundh, L., \& Ardö, J., 2005. A recent greening of the Sahel-trends, patterns and potential causes. Journal of Arid Environments, 63, 556-566 
Pauleit, S., \& Duhme, F., 2000. Assessing the environmental performance of land cover types for urban planning. Landscape and Urban Planning, 52, 1-20

Ranta, H., Kubin, E., Siljamo, P., Sofiev, M., Linkosalo, T., Oksanen, A., \& Bondestam, K., 2006. Long distance pollen transport cause problems for determining the timing of birch pollen season in Fennoscandia by using phenological observations. Grana, 45, 297-304

Reed, B.C., Brown, J.F., VanderZee, D., Loveland, T.R., Merchant, J.W., \& Ohlen, D.O., 1994. Measuring phenological variability from satellite imagery. Journal of Vegetation Science, 5, 703-714

Reed, B., Schwartz, M., \& Xiao, X., 2009. Remote Sensing Phenology. In A. Noormets (Ed.), Phenology of Ecosystem Processes (pp. 231-246): Springer New York

Roerink, G.J., Danes, M.H.G.I., Prieto, O.G., de Wit, A.J.W., \& van Vliet, A.J.H., 2011. Deriving plant phenology from remote sensing. In, Analysis of Multi-temporal Remote Sensing Images (Multi-Temp), 2011 6th International Workshop on the (pp. 261-264)

Sabariego, S., Pérez-Badia, R., Bouso, V., \& Gutiérrez, M., 2011. Poaceae pollen in the atmosphere of Aranjuez, Madrid and Toledo (central Spain). Aerobiologia, 27, 221-228

Sánchez Mesa, J.A., Smith, M., Emberlin, J., Allitt, U., Caulton, E., \& Galan, C., 2003. Characteristics of grass pollen seasons in areas of southern Spain and the United Kingdom. Aerobiologia, 19, 243-250

Seaquist, J.W., Hickler, T., Eklundh, L., Ardö, J., \& Heumann, B.W., 2009. Disentangling the effects of climate and people on Sahel vegetation dynamics. Biogeosciences, 6, 469-477

Skjøth, C.A., Sommer, J., Brandt, J., Hvidberg, M., Geels, C., Hansen, K., Hertel, O., Frohn, L., \& Christensen, J., 2008a. Copenhagen - a significant source of birch (Betula) pollen? International Journal of Biometeorology, 52, 453-462

Skjøth, C.A., Geels, C., Hvidberg, M., Hertel, O., Brandt, J., Frohn, L.M., Hansen, K.M., Hedegaard, G.B., Christensen, J.H., \& Moseholm, L., 2008b. An inventory of tree species in Europe-An essential data input for air pollution modelling. Ecological Modelling, 217, 292-304

Skjøth, C.A., Branko, Š., Siegfried, J.g., \& EAN-Network., 2013a. Pollen sources. In M.S.a.K.-C. Bergmann (Ed.), A Review of the Production, Release, Distribution and Health Impacts (pp. 9-27)

Skjøth, C.A., Ørby, P.V., Becker, T., Geels, C., Schlünssen, V., Sigsgaard, T., Bønløkke, J.H., Sommer, J., Søgaard, P., \& Hertel, O., 2013b. Identifying urban sources as cause of elevated grass pollen concentrations using GIS and remote sensing. Biogeosciences, 10, 541-554 
Skjøth, C.A., Baker, P., Sadys M., Adams-Groom, B., 2015a. Pollen from alder (Alnus sp.), birch (Betula sp.) and oak (Quercus sp.) in the UK originate from small woodlands. Urban Climate, 14, 414-428

Skjøth C.A, Bilinska D, Werner M, Malkiewicz M, Adams-Groom B, Kryza M \& Drzeniecka-Osiadacz A., 2015b. Footprint areas of pollen from alder (Alnus) and birch (Betula) in the UK (Worcester) and Poland (Wroclaw) during 2005-2014. Acta Agrobotanica, 68(4): 315-324

Smith, M., \& Emberlin, J., 2005a. Constructing a 7-day ahead forecast model for grass pollen at north London, United Kingdom. Clinical \& Experimental Allergy, 35, 1400-1406

Smith, M., Emberlin, J., \& Kress, A., 2005b. Examining high magnitude grass pollen episodes at Worcester, United Kingdom, using back-trajectory analysis. Aerobiologia, 21, 85-94

Smith, M., Emberlin, J., Stach, A., Rantio-Lehtimäki, A., Caulton, E., Thibaudon, M., Sindt, C., Jäger, S., Gehrig, R., Frenguelli, G., Jato, V., Rajo, F.J., Alcázar, P., \& Galán, C., 2009. Influence of the North Atlantic Oscillation on grass pollen counts in Europe. Aerobiologia, 25, 321-332

Spieksma, F. T. M., Frenguelli, G., Nikkels, A. H., Mincigrucci, G., Smithuis, L. O. M. J., Bricchi, E., et al., 1989. Comparative study of airborne pollen concentrations in central Italy and the Netherlands (19821985). Grana 28: 25-36.

Stach, A., Smith, M., Prieto Baena, J.C., \& Emberlin, J., 2008. Long-term and short-term forecast models for Poaceae (grass) pollen in Poznań, Poland, constructed using regression analysis. Environmental and Experimental Botany, 62, 323-332

Sutherland, I.E., \& Hodgman, G.W., 1974. Reentrant polygon clipping. Commun. ACM, 17, 32-42

Vandijk, A., Callis, S. L., Sakamoto, C. M., \& Decker, W. L., 1987. Smoothing vegetation index profiles - An alternative method for reducing radiometric disturbance in NOAA/AVHRR Data. Photogrammetric Engineering and Remote Sensing, 53

Varney, V., Durham, S., \& Kay, A., 1991 . Allergenic pollen and pollinosis in the United Kingdom. In: G D'Amato, FTM Speiksma and S Bonini (eds.) Allergenic Pollen and Pollinosis in Europe: Blackwell Scientific Publications

White, M.A., Hoffman, F., Hargrove, W.W., \& Nemani, R.R., 2005. A global framework for monitoring phenological responses to climate change. Geophysical Research Letters, 32, L04705

White, M.A., \& Nemani, R.R., 2006. Real-time monitoring and short-term forecasting of land surface phenology. Remote Sensing of Environment, 104, 43-49 
Viovy, N., Arino, O., \& Belward, A.S., 1992. The Best Index Slope Extraction ( BISE): A method for reducing noise in NDVI time-series. International Journal of Remote Sensing, 13, 1585-1590

Zhang, X., Friedl, M.A., Schaaf, C.B., \& Strahler, A.H., 2004. Climate controls on vegetation phenological patterns in northern mid- and high latitudes inferred from MODIS data. Global change biology., 10, $1133-1145$

Zink K., Vogel H., Vogel B., Magyar D., Kottmeier C., 2012. Modeling the dispersion of Ambrosia artemisiifolia L. pollen with the model system COSMO-ART. International Journal of Biometeorology $56,669-680$.

Zink K Kaufmann P, Petitpierre B, Broennimann O, Guisan A, Gentilini E, Rotach MW., 2016. Numerical ragweed pollen forecasts using different source maps: a comparison for France. International Journal of Biometeorology.

List of Figure Captions

Fig.1 Source land cover types relevant to grass and birch and the location of the pollen monitoring stations.

Fig.2 Raw and smoothed MTCI time-series for one pixel for one year and the position of the estimated phenological parameters (i.e. onset of season, onset of pollen season for birch, onset of pollen season for grass, peak of season and pnd of season).

Fig. 3 Determination of flowering season of birch and grass as 25\% (square shape on the broad leaf forest profile) and $75 \%$ (square shape on the grassland profile) of the maximum value of MTCI, respectively, from the onset of the season (circular shape). The birch and grass pollen profiles (seasons) at Worcester are shown.

Fig.4 Estimated standard error $(\mathrm{S})$ and coefficient of determination (R-Sq) derived from the regression line for $(N=54)$ points of the observed start dates of grass (top $(\mathrm{a}, \mathrm{b}, \mathrm{c}))$ and birch (bottom $(\mathrm{d}, \mathrm{e}, \mathrm{f}))$ seasons from pollen concentration ( $y$-axis) and the estimated start dates from grassland MTCI and broad leaf forest MTCI within a $50 \mathrm{~km}$ buffer around the nine pollen monitoring sites for the period of 8 years.

Fig.5 North-to-south trend in the start date of (a) grass and (b) birch pollen seasons estimated by the DM, $\Sigma 75$ and $\Sigma 125$ methods.

Fig.6 Regression of pollen start date estimated using the (a, d) DM, (b, e) $\Sigma 75$ and (c, f) $\Sigma 125$ methods for (a, b, c) grass pollen and (d, e, f) birch pollen against MTCI start date (onset of pollen season) for (a, b, c) grassland and $(\mathrm{d}, \mathrm{e}, \mathrm{f})$ broadleaf forest within a $50 \mathrm{~km}$ buffer around the nine pollen monitoring sites, for a random selection of 18 of the possible points. Estimated standard error $(\mathrm{S})$ and coefficient of determination $(\mathrm{R}-\mathrm{Sq})$ are shown. 
Fig.7 8-year average MTCI-based map of onset of flowering of grassland as a source of grass pollen. The map depicts the spatial variation in the onset of flowering coincidental with the start of pollen season.

Fig.8 8-year average MTCI-based onset flowering map of broadleaf forest as a source of birch pollen. The map depicts the spatial variation in the onset of flowering coincidental with the start of the pollen season.

Table 1 Location of the pollen traps and name of the meteorological stations. Average maxumim and mimimum temperatures $\left({ }^{\circ} \mathrm{C}\right)$ for the July and November 2008 across the sites, the (nan) indicates that the November observations were not available.

\begin{tabular}{|c|c|c|c|c|c|}
\hline Meteorological station name & Site of pollen traps & Latitude & Longitude & $\begin{array}{l}\text { Max. tem } \\
\text { (July,Nov) }\end{array}$ & $\begin{array}{l}\text { Min. tem } \\
\text { (July, Nov) }\end{array}$ \\
\hline Cambridge: botanic garden & Cambridge & 52.1935 & 0.13113 & $22.6,7.6$ & $12.5,1$ \\
\hline Belfast: Ravenhill road & Belfast & 54.5837 & -5.90879 & $19.6,7.4$ & $13.2,1.9$ \\
\hline Wight: Shanklin & IOWT( Isle of wight) & 50.6231 & -1.17934 & $19.2,8.2$ & $13.2,2.8$ \\
\hline Pershore & Worcester & 52.148 & -2.03979 & 19.5 , nan & 13.8 , nan \\
\hline Cardiff: Bute park & Cardiff & 51.4878 & -3.18728 & 21.2, nan & 12.5 , nan \\
\hline $\begin{array}{l}\text { Edinburgh: royal botanic } \\
\text { garden no. } 2\end{array}$ & Edinburgh & 55.9667 & -3.21063 & $19,6.9$ & $12.4,0.8$ \\
\hline Mylnefield & Invergowrie & 56.457 & -3.07182 & $18.6,6.7$ & $11.7,0.3$ \\
\hline London meteorological centre & London & 51.521 & -0.11088 & $21.5,7.2$ & $16.7,4.4$ \\
\hline Plymouth: Mountbatten & Plymouth & 50.3544 & -4.11986 & $17.5,7$ & $13.9,4$ \\
\hline
\end{tabular}

Table 2. 8-year average correlation between onset of the birch season defined from the pollen concentration (Derivative Method (DM), Cumulative Sum 75 and 125( $\Sigma 75, \Sigma 125)$, and defined from the MTCI (25\% Maximum value of MTCI from SOS) for the nine stations across the UK.

\begin{tabular}{lccccccc}
\hline \multirow{2}{*}{$\begin{array}{c}\text { Station } \\
\mathrm{N}\end{array}$} & Year & MTCI & \multicolumn{2}{c}{ DM } & \multicolumn{2}{c}{$\Sigma 75$} & \multicolumn{2}{c}{$\Sigma 125$} \\
\cline { 4 - 8 } ave.8y & Day & $r$ & Day & $r$ & Day & $r$ & Day \\
\hline Belfast & 97 & $0.891 * *$ & 107 & $0.962 * *$ & 107 & $0.937 * *$ & 110 \\
Cambridge & 85 & & 94 & & 96 & 97 \\
Cardiff & 92 & & 98 & & 99 & 101 \\
Edinburgh & 99 & & 100 & & 105 & 107 \\
Invergowrie & 101 & & 107 & & 109 & 111 \\
IOWT & 87 & & 98 & & 99 & 102 \\
London & 79 & & 92 & & 92 & 94 \\
Plymouth & 88 & & 98 & & 100 & 102 \\
Worcester & 86 & & 93 & & 95 & 96 \\
**. Correlation is significant at the 0.01 level $*$ Correlation is significant at the 0.05 level
\end{tabular}

**. Correlation is significant at the 0.01 level *. Correlation is significant at the 0.05 level 
Table 3. Relationship between onset of birch season defined from the pollen concentration (Derivative Method (DM), Cumulative Sum 75 and 125 ( $\Sigma 75, \Sigma 125)$, and defined from the MTCI (25\% Maximum value of MTCI from SOS) for nine stations across the UK.

\begin{tabular}{|ccccccc|}
\hline \multirow{2}{*}{ Year } & \multicolumn{2}{c}{ DM } & \multicolumn{2}{c}{$\Sigma 75$} & \multicolumn{2}{c|}{$\Sigma 125$} \\
\cline { 2 - 7 } Birch & $r$ & St error & $r$ & St error & $r$ & St error \\
\hline 2003 & 0.590 & 7.4 & $0.880^{* *}$ & 4.8 & $0.913 * *$ & 3.7 \\
2004 & $0.800^{* *}$ & 6.6 & $0.764 *$ & 7.1 & $0.784^{*}$ & 6.9 \\
2005 & $0.725^{*}$ & 5.5 & $0.737 *$ & 5.4 & $0.782 *$ & 4.9 \\
2006 & 0.603 & 5.2 & 0.606 & 5.1 & 0.600 & 5.2 \\
2007 & 0.391 & 8.7 & $0.770^{*}$ & 6.0 & $0.720^{*}$ & 6.5 \\
2008 & $0.803 * *$ & 6.6 & $0.870^{* *}$ & 5.4 & $0.862 * *$ & 5.6 \\
2009 & $0.698^{*}$ & 5.4 & $0.755^{*}$ & 4.9 & $0.761 *$ & 4.9 \\
2010 & $0.902 * *$ & 3.4 & $0.730^{*}$ & 5.4 & $0.779 *$ & 4.9 \\
Aver. & $0.891 * *$ & 3.4 & $0.962 * *$ & 2.0 & $0.937 * *$ & 2.6 \\
\hline
\end{tabular}

**. Correlation is significant at the 0.01 level $*$. Correlation is significant at the 0.05 level

Table 4. 8-year average correlation between onset of the grass season defined from the pollen concentration (Derivative Method (DM), Cumulative Sum 75 and 125( $\Sigma 75, \Sigma 125)$, and defined from the MTCI (75\% Maximum value of MTCI from SOS) for the nine stations across the UK.

\begin{tabular}{|c|c|c|c|c|c|c|c|c|}
\hline \multirow{2}{*}{$\begin{array}{l}\quad \text { Station } \\
\mathrm{N} \\
\end{array}$} & \multirow{2}{*}{$\begin{array}{c}\text { Year } \\
\text { ave.8y }\end{array}$} & \multirow{2}{*}{$\begin{array}{c}\text { MTCI } \\
\text { Day }\end{array}$} & \multicolumn{2}{|c|}{ DM } & \multicolumn{2}{|c|}{$\Sigma 75$} & \multicolumn{2}{|l|}{$\Sigma 125$} \\
\hline & & & $r$ & Day & $r$ & Day & $r$ & Day \\
\hline Belfast & & 152 & $0.839 * *$ & 158 & $0.932 * *$ & 150 & $0.944 * *$ & 156 \\
\hline Cambridge & & 138 & & 150 & & 143 & & 148 \\
\hline Cardiff & & 151 & & 154 & & 153 & & 156 \\
\hline Edinburgh & & 152 & & 160 & & 156 & & 161 \\
\hline Invergowrie & & 156 & & 162 & & 158 & & 162 \\
\hline IOWT & & 139 & & 143 & & 138 & & 145 \\
\hline London & & 140 & & 152 & & 144 & & 149 \\
\hline Plymouth & & 146 & & 150 & & 144 & & 149 \\
\hline Worcester & & 138 & & 150 & & 139 & & 146 \\
\hline
\end{tabular}

**. Correlation is significant at the 0.01 level *. Correlation is significant at the 0.05 level 
Table 5. Relationship between onset of grass season defined from the pollen concentration (Derivative Method (DM), Cumulative Sum 75 and 125( $\Sigma 75, \Sigma 125)$, and defined from the MTCI (75\% Maximum value of MTCI from SOS) for nine stations across the UK.

\begin{tabular}{|ccccccc|}
\hline \multirow{2}{*}{ Year } & \multicolumn{2}{c}{ DM } & \multicolumn{2}{c}{$\Sigma 75$} & \multicolumn{2}{c|}{$\Sigma 125$} \\
\cline { 2 - 7 } Grass & $r$ & St error & $r$ & St error & $r$ & St error \\
\hline 2003 & $0.883^{* *}$ & 3.3 & $0.682^{*}$ & 5.2 & $0.877^{* *}$ & 3.4 \\
2004 & $0.685^{*}$ & 3.8 & $0.793^{*}$ & 3.2 & $0.798^{* *}$ & 3.2 \\
2005 & 0.611 & 8.9 & $0.816^{* *}$ & 6.5 & $0.773^{*}$ & 7.1 \\
2006 & $0.704^{*}$ & 6.0 & 0.604 & 6.8 & $0.755^{*}$ & 5.6 \\
2007 & $0.904^{* *}$ & 2.4 & $0.831^{* *}$ & 3.1 & $0.896^{* *}$ & 2.5 \\
2008 & 0.325 & 5.8 & $0.815^{* *}$ & 3.5 & $0.823^{* *}$ & 3.5 \\
2009 & $0.678^{*}$ & 11.6 & $0.789 *$ & 9.7 & $0.755^{*}$ & 10.4 \\
2010 & 0.562 & 7.7 & $0.781^{*}$ & 5.8 & $0.804^{* *}$ & 5.6 \\
Aver. & $0.839^{* *}$ & 4.1 & $0.932^{* *}$ & 2.7 & $0.944^{* *}$ & 2.5 \\
\hline
\end{tabular}

**. Correlation is significant at the 0.01 level *. Correlation is significant at the 0.05 level 